OPEN ACCESS

Edited by:

Evangelos Topakas,

National Technical University

of Athens, Greece

Reviewed by:

Heiko Lange,

University of Naples Federico II, Italy

Artur Ribeiro,

University of Minho, Portugal

Shaoni Sun,

Beijing Forestry University, China

${ }^{*}$ Correspondence:

Chen Liang

liangchen@gxu.edu.cn

Caoxing Huang

hcx@njfu.edu.cn

tThese authors have contributed equally to this work and share first

authorship

Specialty section:

This article was submitted to Industrial Biotechnology,

a section of the journal

Frontiers in Bioengineering and

Biotechnology

Received: 24 June 2020

Accepted: 31 August 2020 Published: 25 September 2020

Citation:

Pei W, Chen ZS, Chan HYE, Zheng L, Liang C and Huang C (2020) Isolation and Identification of a Novel Anti-protein Aggregation Activity of Lignin-Carbohydrate Complex

From Chionanthus retusus Leaves. Front. Bioeng. Biotechnol. 8:573991. doi: 10.3389/fbioe.2020.573991

\section{Isolation and Identification of a Novel Anti-protein Aggregation Activity of Lignin-Carbohydrate Complex From Chionanthus retusus Leaves}

\author{
Wenhui Pei ${ }^{1,2 t}$, Zhefan Stephen Chen ${ }^{3,44}$, Ho Yin Edwin Chan ${ }^{3,4}$, Liming Zheng ${ }^{5}$, \\ Chen Liang ${ }^{1 *}$ and Caoxing Huang ${ }^{1,2 *}$ \\ ' Guangxi Key Laboratory of Clean Pulp \& Papermaking and Pollution Control, Guangxi University, Nanning, China, \\ ${ }^{2}$ Co-Innovation Center of Efficient Processing and Utilization of Forest Resources, Department of Bioengineering, Nanjing \\ Forestry University, Nanjing, China, ${ }^{3}$ Nexus of Rare Neurodegenerative Diseases, School of Life Sciences, Faculty \\ of Science, The Chinese University of Hong Kong, Shatin, China, ${ }^{4}$ Gerald Choa Neuroscience Centre, The Chinese \\ University of Hong Kong, Shatin, China, ${ }^{5}$ State Key Laboratory of Pharmaceutical Biotechnology, Department of Sports \\ Medicine and Adult Reconstructive Surgery, Nanjing Drum Tower Hospital, The Affiliated Hospital of Nanjing University \\ Medical School, Nanjing, China
}

Lignin-carbohydrate complex (LCC) is the biological macromolecule that has been demonstrated to exert multiple biological functions, including antioxidant, antiinflammation and anti-tumorigenesis, which support its broad application in the bioengineering field. However, it remains elusive the involvements of LCC in human neurological disorders, especially those with the overproduction of reactive oxygen species (ROS), such as spinocerebellar ataxias (SCAs). In this study, we found a previously undetermined anti-protein aggregation activity of LCC. Initially, two individual LCC preparations and carbohydrate-free lignin were isolated from the water-extracted waste residues of Chionanthus retusus (C. retusus) tender leaves. The chemical compositional analysis revealed that lignin $(61.5 \%)$ is the predominant constituent in the lignin-rich LCC (LCC-L-CR), whereas the carbohydrate-rich LCC (LCC-C-CR) is mainly composed of carbohydrate (60.9\%) with the xylan as the major constituent (42.1\%). The NMR structural characterization showed that LCC-L-CR preparation is enriched in benzyl ether linkage, while phenyl glycoside is the predominant type of linkage in LCC-C-CR. Both LCC and lignin preparations showed antioxidant activities as exemplified by their abilities to scavenge free radicals in cultured mammalian cells and ROS in zebrafish. We further demonstrated a pronounced capability of LCC-L-CR in inhibiting the aggregation of expanded Ataxin-3, disease protein of SCA type 3, in human neuronal cells. Taken together, our study highlights the antioxidant and novel anti-protein aggregation activities of the C. retusus tender leaves-derived LCC.

Keywords: Chionanthus retusus leaves, lignin-carbohydrate complex, antioxidant, anti-protein aggregation, reactive oxygen species 


\section{INTRODUCTION}

Chionanthus retusus Lindl. et Paxton (C. retusus) contains various types of deciduous trees that are distributed across tropical and subtropical Asian countries, including China, Japan, North Korea, and South Korea (Arias et al., 2011). The tender leaf from $C$. retusus has been widely used in preparing medicinal tea or consumed beverages due to its abundance in polyphenols, flavonoids, and functional polysaccharides (Lee et al., 2019). Generally, the hot water $\left(90-100^{\circ} \mathrm{C}\right)$ extraction (or "steeping") predominantly releases water soluble constituents (tea polyphenols, theophylline, amino acids, and vitamins) from roasted tender leaves, leaving the majority of polysaccharides (cellulose and hemicellulose) and lignin in the residual solids (Liu et al., 2018; Fu et al., 2020). These residual solids are initially considered as agricultural residues for disposal or burning, which can lead to severe environmental contamination and air pollution. However, recently, emerging evidence has demonstrated that both polysaccharides and lignin from residual solids are invaluable resources for preparing multiple kinds of bio-materials and bio-chemicals using a biorefinery-type process (Chen D. et al., 2018; Zhao et al., 2018; Wu et al., 2019; Pei et al., 2020; Wei et al., 2020). Therefore, an ideal and greener waste management alternative should be considered to reuse the residual solids from $C$. retusus leaves.

For C. retusus, cellulose, hemicellulose and lignin are physically and chemically interlinked within the cell wall (Ten and Vermerris, 2013; Song and Hong, 2020). Anatomically, lignin and carbohydrate (mainly xylan) that are covalently linked via benzyl ethers, benzyl esters and phenyl glycoside moieties are referred to as lignin-carbohydrate complexes (LCCs) (Dong et al., 2020; Lin et al., 2020; Wang et al., 2020). Compared to neat lignin, the carbohydrate portions in LCCs could facilitate their recognition by cells, thus improving the cellular compatibilities of LCCs (Jiang et al., 2010). The LCCs function as oxidative stress suppressors and immune stimulants (Huang et al., 2019; Jiang et al., 2019). For example, Zhang et al. (2018) used the hot-water extraction liquor from spruce wood to isolate the LCC fraction, which exhibits pronounced activity toward scavenging free radicals in vitro. Dong et al. (2020) demonstrated the isolation of carbohydrate-rich LCC preparations from different biomass, and they found that these LCCs possess strong capabilities toward scavenging intracellular and endogenous reactive oxygen species (ROS). Given its antioxidant activity, LCC has been widely implicated in executing anti-tumor, anti-microbial, anti-parasite, and anti-viral functions (Sakagami et al., 2005, 2010). Therefore, we are intended to investigate the potential biological functions of LCCs isolated from the water-extracted residual solids of C. retusus tender leaves.

The excessive production of ROS in cells leads to oxidative stress, which contributes to a group of human disorders including cancer, diabetes, inflammatory diseases, and neurodegenerative diseases (Waris and Ahsan, 2006). The abnormal genetic expansion of polyglutamine (polyQ) tract is causative for a specific group of neurodegenerative disorders known as polyQ diseases, which include Huntington's disease and several subtypes of spinocerebellar ataxias (SCAs) (Lieberman et al., 2019). As the pathological hallmark of polyQ diseases, the formation of polyQ protein aggregates in neurons impairs a range of normal biological functions and contributes to polyQ neurodegeneration (Adegbuyiro et al., 2017). A series of chemical inhibitors, including small molecule compound (Hong et al., 2019), synthetic peptide (Nagai et al., 2003) and natural product extract (Walter et al., 2014), have been reported to ameliorate polyQ cytotoxicity via lowering the level of polyQ protein aggregates. Moreover, several lines of evidence have demonstrated the neuroprotective roles of antioxidants in polyQ diseases ( $\mathrm{Wu}$ et al., 2017; Essa et al., 2019). However, no reports have ever demonstrated the potential relationship between LCC and polyQ diseases. It would therefore be interesting to investigate whether the LCCs isolated from C. retusus leaves would elicit any modulatory effect on polyQ pathogenesis.

In the current study, we used hot-water extracted residual solids from C. retusus tender leaves as feedstock to isolate two independent carbohydrate (LCC-C-CR) and lignin enriched (LCC-L-CR) LCC preparations, the carbohydrate-free lignin preparation (Lignin-CR) was isolated simultaneously. Their chemical structures were further comprehensively characterized using size exclusion chromatography and NMR. The in vitro mammalian cell and in vivo zebrafish models were used to evaluate the antioxidant activities of LCC-C-CR, LCC-L-CR, and Lignin-CR, and all of them showed scavenging capabilities toward free radicals and endogenous ROS. Moreover, we found that treatment of LCC-L-CR suppresses polyQ protein aggregation in neuronal cells. Taken together, our study is the first report to demonstrate the novel anti-protein aggregation activity of LCC. This contributes to the broaden application of LCC in the biological and bioengineering fields, and further suggests the potential benefits of LCC on protecting neuronal dysfunctions in human protein misfolding diseases.

\section{MATERIALS AND METHODS}

\section{C. retusus Tender Leaves}

Tender leaves from C. retusus tree (5 years old, locked in Suqian, Jiangsu, China) were collected in the spring of 2019. The fresh leaves were dried at $90^{\circ} \mathrm{C}$ for $5 \mathrm{~h}$ before immediately ground into the powder with particle sizes between 20 and 40 mesh. The obtained powder was stored at $4^{\circ} \mathrm{C}$ for further study and analysis.

\section{Isolation and Purification of LCC and Lignin Preparations From C. retusus Leaf Powder}

The C. retusus tender leaf powder was steeped in hot water $\left(95^{\circ} \mathrm{C}\right)$ for $2 \mathrm{~h}$ in order to imitate the process of tea beverage preparation. After steeping, the hot-water extracted residual solid (ERDS) were separated and dried at $40^{\circ} \mathrm{C}$, followed by the extraction with benzene/ethanol $(2: 1, \mathrm{v} / \mathrm{v})$ in a Soxhlet extractor for $12 \mathrm{~h}$ to remove pigments and alcohol-soluble substances.

Lignin-rich LCC, carbohydrate-rich LCC and lignin fractions were then prepared from the extracted ERDS according to the classical method described by Bjoörkman (1957). Briefly, ERDS 
( $\sim 4 \mathrm{~g}$ ) was subjected to planetary ball milling in a $100 \mathrm{~mL} \mathrm{ZrO}_{2}$ bowl with $25 \mathrm{ZrO}_{2}$ balls at $600 \mathrm{rpm}$ for $5 \mathrm{~h}$. Milled ERDS was then extracted using aqueous dioxane $(96 \%, \mathrm{v} / \mathrm{v})$ at solid to liquid ratio of $1: 10(\mathrm{~g} / \mathrm{mL})$ at room temperature for $24 \mathrm{~h}$. This process was repeated three times, and then the extracted solutions were combined and evaporated under vacuum at $40^{\circ} \mathrm{C}$. The ligninrich LCC and lignin in the extracted solutions were also purified according to the standard protocol in Bjoörkman's (1957) work. Next, the residual matter after triple dioxane extraction was washed with distilled water to remove all traces of dioxane. From this washed matter, the carbohydrate-rich LCC preparation was isolated using an acetic acid solution (50\%, v/v) and purified according to the standard protocol in Bjoörkman (1957). The lignin-rich LCC, carbohydrate-rich LCC and lignin fractions from ERDS of C. retusus were termed LCC-L-CR, LCC-C-CR and Lignin-CR, respectively.

\section{Chemical Compositional Analysis of C. retusus, LCC and Lignin Preparations}

The chemical compositions (carbohydrates and lignin) of raw C. retusus tender leaf, hot water extracted $C$. retusus tender leaf, LCC and lignin preparations were analyzed according to the procedures developed by the National Renewable Energy Laboratory (Sluiter et al., 2011). The monosaccharides in all samples were analyzed by high-performance anion exchange chromatography system (Dionex ISC 5000, Sunnyvale, CA, United States), which was equipped with the PA10 $(2 \times 250 \mathrm{~mm})$ column and pulsed amperometric detector (Zhou and Xu, 2019). The amount of polyphenols in the LCC and lignin preparations was determined according to Folin-Ciocalteu method using gallic acid as a calibration standard by UV-vis spectrophotometer at $745 \mathrm{~nm}$ (Singleton and Rossi, 1965). The samples were prepared according to our previous work (He et al., 2020).

\section{Molecular Weights Analysis of LCC and Lignin Preparations}

Weight-average $\left(M_{w}\right)$ and number-average $\left(M_{n}\right)$ molecular weights of LCC and lignin preparations were measured using a gel permeation chromatography (GPC) system equipped with the PL-gel $10 \mathrm{~mm}$ and mixed-B $7.5 \mathrm{~mm}$ i.d. column and an ultraviolet detector. The samples were fully dissolved in tetrahydrofuran (THF) at the concentration of $1 \mathrm{mg} / \mathrm{mL}$. Monodisperse polystyrenes (Sigma) with 1320, 9200, 66,000, $435,500 \mathrm{~g} / \mathrm{mol}$ were used as the standards to calculate the molecular weights. The analysis procedures were carried out at $35^{\circ} \mathrm{C}$ with $\mathrm{THF}$ as eluent with flowing rate of $1 \mathrm{~mL} / \mathrm{min}$.

\section{NMR Analysis of LCC and Lignin Preparations}

Complete structural information (sub-units, lignin linkages, and lignin-carbohydrate linkages) of both LCC and lignin preparations was determined using a Bruker AVANCE $600 \mathrm{MHz}$ spectrometer, in which the quantitative ${ }^{13} \mathrm{C}$ NMR and $2 \mathrm{D}$ HSQC NMR spectra were obtained using dimethyl sulfoxide- $\mathrm{d}_{6}$ (DMSO- $\mathrm{d}_{6}$ ) as the solvent. The sample preparation steps for NMR analysis were described previously (Dong et al., 2020). For
${ }^{13} \mathrm{C}$ NMR analysis, the acquisition parameters were $25^{\circ} \mathrm{C}, 90^{\circ}$ pulse width, $1.7 \mathrm{~s}$ relaxation, and $1.2 \mathrm{~s}$ of acquisition time. For 2D-HSQC NMR analysis, 160 transients (scans per block) were acquired using 1024 data points in F2 $\left({ }^{1} \mathrm{H}\right)$ dimension with an acquisition time of $53 \mathrm{~ms}$ and 256 data points and $\mathrm{F} 1\left({ }^{13} \mathrm{C}\right)$ dimension with an acquisition time of $5.14 \mathrm{~ms}$. The amounts (per $\left.100 \operatorname{Ar}\left(\mathrm{C}_{900}\right)\right)$ of lignin linkages and lignin-carbohydrate linkages in both LCC samples were calculated from a combination of quantitative ${ }^{13} \mathrm{C}$ and $2 \mathrm{D}$ HSQC NMR according to Zhang and Gellerstedt (2007) using the following formulas:

$$
\begin{gathered}
\mathrm{Ix}=2 \mathrm{DI}_{\mathrm{x}} / 2 \mathrm{DI}_{78-90 / 2.5-6.0} \times \\
{ }^{13} \mathrm{C}_{78-90} /{ }^{13} \mathrm{C}_{103-163} \times 600 \\
\mathrm{BE}=2 \mathrm{D}_{\mathrm{BE}} / 2 \mathrm{D}_{78-90 / 3.0-5.7} \times \\
{ }^{13} \mathrm{C}_{78-90} /{ }^{13} \mathrm{C}_{103-163} \times 600 \\
\mathrm{PhGlc}=2 \mathrm{D}_{\mathrm{PhGlc}} / 2 \mathrm{D}_{96-103 / 3.8-5.5} \times \\
{ }^{13} \mathrm{C}_{96-103} /{ }^{13} \mathrm{C}_{103-163} \times 600 \\
\gamma-\mathrm{Est}=2 \mathrm{D}_{\mathrm{Est}} / 2 \mathrm{D}_{58-65 / 2.5-5.0} \times \\
{ }^{13} \mathrm{C}_{58-65} /{ }^{13} \mathrm{C}_{103-163} \times 600
\end{gathered}
$$

In the formulas, $\mathrm{I}_{\mathrm{x}}$ is the integral value of $a$ position signal in lignin linkages $(\beta-\mathrm{O}-4, \beta-\beta$, and $\beta-5)$ in the $2 \mathrm{D}$ spectra region. BE, PhGlc, and $\gamma$-Est are the amounts of benzyl ether, phenyl glycoside, and $\gamma$-ester LCC linkages. During the integration process, all the integration was conducted at the same contour level.

The contents of aliphatic hydroxyl and phenolic hydroxyl in LCC and lignin preparations were determined by quantitative ${ }^{31} \mathrm{P}$ NMR using a Bruker AVANCE $600 \mathrm{MHz}$ spectrometer, in which endo- $N$-hydroxy-5-norbornene-2, 3-dicarboximide (e-NHI) was used as the internal standard. The samples [ $40 \mathrm{mg}$ of solid was dissolved in $0.5 \mathrm{~mL}$ of anhydrous pyridine/ $\mathrm{CDCl}_{3}$ mixture (1.6:1, $\mathrm{v} / \mathrm{v})$ ] were prepared according to our previous report (Huang et al., 2017). The acquisition parameters with a total number of 256 scans were used to obtain the spectra in ${ }^{31} \mathrm{P}$ NMR analysis.

\section{Preparation of LCC and Lignin Stock Solutions for Biological Experiments}

The LCC-C-CR, LCC-L-CR and Lignin-CR samples were dissolved in dimethylsulfoxide (DMSO) to prepare the stock solutions at $25 \mathrm{mg} / \mathrm{mL}$. The solutions were briefly sonicated (30 s) in ultrasonic bath (DC-80H, Healthcare Technologies) to dissolve all the matters before being used in the subsequent biological experiments.

\section{Antioxidant Activity Analysis of LCC and Lignin Preparations}

Both in vitro mammalian cell and in vivo zebrafish experimental models were used to evaluate antioxidant activities of LCC and lignin preparations. The measurements of scavenging capabilities on 2,2-diphenyl-1-picryl-hydrazyl (DPPH) and superoxide anion $\left(\mathrm{O}_{2}{ }^{\bullet-}\right)$ radicals in RAW 264.7 cells, and endogenous ROS 
in zebrafish were carried out as described previously (Dong et al., 2020). For DPPH scavenging assay, the RAW 264.7 cells were treated with LCC or lignin preparations at $0.005 \mathrm{mg} / \mathrm{mL}$, $0.01 \mathrm{mg} / \mathrm{mL}, 0.02 \mathrm{mg} / \mathrm{mL}, 0.05 \mathrm{mg} / \mathrm{mL}, 0.1 \mathrm{mg} / \mathrm{mL}$, and $0.2 \mathrm{mg} / \mathrm{mL}$. For $\mathrm{O}_{2}{ }^{\bullet-}$ scavenging assay, the RAW 264.7 cells were treated with LCC or lignin preparations at $0.1 \mathrm{mg} / \mathrm{mL}$, $0.2 \mathrm{mg} / \mathrm{mL}, 0.4 \mathrm{mg} / \mathrm{mL}, 0.6 \mathrm{mg} / \mathrm{mL}, 0.8 \mathrm{mg} / \mathrm{mL}, 1.0 \mathrm{mg} / \mathrm{mL}$, and $2.0 \mathrm{mg} / \mathrm{mL}$. For ROS scavenging assay, the zebrafish was treated with LCC or lignin preparations at $200 \mu \mathrm{g} / \mathrm{mL}$. All animal experiments were performed following the guiding principles for the care and use of animals approved by the animal ethics committee of Nanjing Drum Tower Hospital, The Affiliated Hospital of Nanjing University Medical School (Permit number: 2019AE01018).

\section{Cytotoxicity Evaluation of LCC and Lignin Preparations}

The cytotoxicities of LCC-C-CR, LCC-L-CR, and Lignin-CR were measured using a CytoTox-Glo ${ }^{\mathrm{TM}}$ Cytotoxicity Assay kit (G9290, Promega) according to the manufacturer's instructions. Briefly, the human neuroblastoma SK-N-MC cells were cultured in 96-well plates and treated with LCC or lignin preparations at $25 \mu \mathrm{g} / \mathrm{mL}, 50 \mu \mathrm{g} / \mathrm{mL}, 100 \mu \mathrm{g} / \mathrm{mL}, 200 \mu \mathrm{g} / \mathrm{mL}, 400 \mu \mathrm{g} / \mathrm{mL}$, and $800 \mu \mathrm{g} / \mathrm{mL}$. The treatment lasted for $24 \mathrm{~h}$. The luminescent intensities were measured on a FLUOstar Omega Microplate Reader (BMG LABTECH). The percentage of live cells was calculated by the following equation:

$$
\begin{gathered}
\text { Percentage of live cells }(\%)= \\
\frac{\text { luminescence }_{\text {total }}-\text { luminescence }_{\text {dead }}}{\text { luminescence }_{\text {total }}} \times 100 \%
\end{gathered}
$$

\section{Generation of $p A c G F P-A T X N 3 Q 71$ Plasmid}

To generate PAcGFP-ATXN3Q71, the ATXN3Q71 DNA fragment amplified from $p E G F P-A T X N 3 Q 78$ was subcloned into the pAcGFP-C1 vector (632470, Clontech) using KpnI and BamHI (Chen Z. S. et al., 2018; Chen et al., 2019). In contrast to EGFP, which is prone to form dimers, AcGFP is a monomeric green fluorescent protein with equivalent brightness (Zacharias et al., 2002; Gurskaya et al., 2003). When AcGFP-ATXN3Q71 was expressed in our cell model, the number of ATXN3Q71 protein aggregates in each cell could be clearly detected and easily counted, while this is more difficult to achieve in EGFPATXNQ78-expressing cells (Hong et al., 2019).

\section{SK-N-MC Cell Culture and Transfection}

Human neuroblastoma cell line SK-N-MC (HTB-10 ${ }^{\mathrm{TM}}$, American Type Culture Collection) was cultured using Dulbecco's Modified Eagle's Medium (11995065, Thermo Fisher Scientific) supplemented with 10\% Fetal Bovine Serum (F7524, Sigma-Aldrich) and $1 \%$ Antibiotic-Antimycotic solution (15240062, Thermo Fisher Scientific). The cells were maintained in a $37^{\circ} \mathrm{C}$ humidified cell culture incubator supplemented with 5\% $\mathrm{CO}_{2}$. Lipofectamine 2000 (11668019, Thermo Fisher Scientific) was used in plasmid transfection.
The $0.5 \mu \mathrm{g}$ of $p A c G F P-A T X N 3 Q 71$ plasmid, together with $1 \mu \mathrm{L}$ of Lipofectamine 2000 (11668019, Thermo Fisher Scientific) were used to transfect SK-N-MC cells, and the transfection lasted for $48 \mathrm{~h}$.

\section{Fluorescence Imaging of ATXN3Q71 Protein Aggregates in SK-N-MC Cells}

The SK-N-MC cells were cultured on coverslips (MarienfeldSuperior). Twenty-four hours post transfection, the cells were treated with LCC or lignin preparations at $100 \mu \mathrm{g} / \mathrm{mL}$ for another $24 \mathrm{~h}$, prior to being harvested for the subsequent fluorescence imaging of ATXN3Q71 protein aggregates. Cells were fixed with 3.7\% paraformaldehyde for $15 \mathrm{~min}$ followed by permeabilization with $0.1 \%$ Triton X-100 for another $15 \mathrm{~min}$. The cell nuclei were stained with DAPI (62248, Thermo Fisher Scientific) at $25^{\circ} \mathrm{C}$ for $5 \mathrm{~min}$. Fluorescence was acquired using a confocal microscope Zeiss LSM (Zeiss) and images were analyzed using Fiji software (Version 2.0.0-rc-69/1.52n, NIH).

\section{Statistical Analysis}

The two-tailed, unpaired Student's $t$-test, or Mann-Whitney $U$ test was used for the comparison of two experimental groups. One-way ANOVA followed by post hoc Tukey's test was applied to determine the difference between each experimental group when comparing three or more groups. ${ }^{*}, * *$, and ${ }^{* * *}$ represent $p<0.05, p<0.01$, and $p<0.001$, respectively, which are considered statistically significant. ns indicates no significant difference. GraphPad Prism (Version 8.1.2) was used for statistical analysis.

\section{RESULTS AND DISCUSSION}

\section{Compositional Analysis of C. retusus Tender Leaf and Its Derived Materials}

We first aimed at investigating the detailed composition of polysaccharides (cellulose and hemicellulose) and lignin in C. retusus tender leaf and its derived materials. The raw C. retusus tender leaf (CR-TL), hot water extracted C. retusus tender leaf (WE-CR-TL), LCC and lignin preparations were used for the compositional analysis (Table 1). The results showed that polysaccharides were more abundant in CR-TL. Among the determined polysaccharides, cellulose (expressed as glucan) was the major component (42.1\%), followed by hemicelluloses (26.1\%), which was composed of xylan (21.1\%), arabinan $(2.5 \%)$, galactan $(1.1 \%)$, and mannan $(1.4 \%)$. The percentage of lignin in CR-TL was $19.5 \%$, which is slightly lower than those in conventional hardwood (20-25\%) and softwood (26$32 \%)$. We hypothesize that this reduction of lignin is likely due to the leaves being 1-3 months in age, which does not allow sufficient lignification to occur. We detected a similar composition of polysaccharides and lignin (according to National Renewable Energy Laboratory procedures) in WE-CR-TL, with the respective amounts of cellulose, hemicellulose and lignin were $49.5 \%, 18.4 \%$, and $22.9 \%$. The percentage of hemicellulose in WE-CR-TL (18.4\%) was lower than what was detected in 
TABLE 1 | Chemical compositions of C. retusus tender leaf, hot water extracted C. retusus tender leaf, LCC and lignin preparations.

\begin{tabular}{|c|c|c|c|c|c|c|c|c|c|}
\hline & \multirow[t]{2}{*}{ Lignin (\%) } & \multirow[t]{2}{*}{ Cellulose (\%) } & \multicolumn{4}{|c|}{ Hemicellulose (\%) } & \multirow[t]{2}{*}{ Polyphenols (\%) } & \multicolumn{2}{|c|}{ Hydroxyl content $(\mathrm{mmol} / \mathrm{g})^{\mathrm{b}}$} \\
\hline & & & Xylan & Arabinan & Galactan & Mannan & & Aliphatic & Phenolic \\
\hline CR-TL ${ }^{a}$ & 19.5 & 42.1 & 21.1 & 2.5 & 1.1 & 1.4 & / & / & / \\
\hline WE-CR-TL ${ }^{a}$ & 22.9 & 49.5 & 17.4 & 0.8 & 0.1 & 0.1 & / & / & / \\
\hline LCC-L-CRa & 61.5 & 6.7 & 23.1 & 0.9 & 0.3 & 0.8 & 2.1 & 3.95 & 1.35 \\
\hline LCC-C-CR ${ }^{a}$ & 31.9 & 9.9 & 42.1 & 6.3 & 1.5 & 1.1 & 1.7 & 4.12 & 1.01 \\
\hline Lignin-CR ${ }^{a}$ & 92.5 & 0.2 & 0.8 & 0.1 & 0 & 0 & 3.5 & 3.65 & 1.89 \\
\hline
\end{tabular}

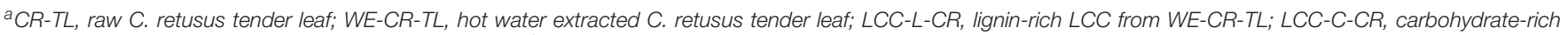
LCC from WE-CR-TL; Lignin-CR, lignin from WE-CR-TL. b Determined by quantitative ${ }^{31} \mathrm{P} N M R$.

CR-TL (26.1\%), indicating a labile portion of hemicellulose undergoes degradation after hot water extraction (Azhar et al., 2015; Gu et al., 2020).

As shown in Table 1, we obtained two distinct LCC preparations, which were enriched in lignin (LCC-L-CR) and carbohydrate (LCC-C-CR), respectively. The carbohydrates in both LCC preparations comprise the same types of sugars, including glucan, xylan, arabinan, galactan, and mannan. Moreover, the types of sugars in our LCCs coincide with those in LCCs derived from hardwood and non-woody biomass (Dong et al., 2020). When looking into the amount of each type of sugars, we found that xylan is the predominant component in both LCC-L-CR (23.1\%) and LCC-C-CR (42.1\%). Meanwhile, the amounts of glucan $(6.7 \%$ and $9.9 \%)$, arabinan $(0.9 \%$ and $6.3 \%)$, galactan $(0.3 \%$ and $1.5 \%)$, and mannan $(0.8 \%$ and $1.1 \%)$ were relatively lower. The compositional analysis was also carried out on carbohydrate-free lignin preparation isolated from C. retusus tender leaf (Lignin-CR). As shown in Table 1, only trace amount of carbohydrate $(1.1 \%)$ was detected, suggesting Lignin-CR as a relatively pure lignin sample.

Given the importance of polyphenols in contributing to the biological functions of biopolymers, the amount of polyphenols in LCC and lignin preparations were further measured (Table 1). We found a slightly higher amount of polyphenols in LigninCR (3.5\%), when compared to LCC-L-CR (2.1\%) and LCC-C-CR (1.7\%). Next, quantitative ${ }^{31} \mathrm{P} \mathrm{NMR}$ was performed with the aim to unveiling the detailed contents of aliphatic and phenolic hydroxyl in LCC and lignin preparations. Both aliphatic and phenolic hydroxyl were detected in LCC-L-CR, LCC-C-CR and Lignin-CR, with the amount of aliphatic hydroxyl (ranging from 3.65 to $4.12 \mathrm{mmol} / \mathrm{g}$ ) was higher than phenolic hydroxyl (ranging from 1.01 to $1.89 \mathrm{mmol} / \mathrm{g}$ ).

\section{Molecular Weight Analysis of LCC and Lignin Preparations}

Molecular weight estimations, including the weight-average molecular weights $\left(\mathrm{M}_{w}\right)$, number-average molecular weights $\left(\mathrm{M}_{\mathrm{n}}\right)$ and polydispersity $\left(\mathrm{M}_{\mathrm{w}} / \mathrm{M}_{\mathrm{n}}\right)$ of $\mathrm{LCC}$ and lignin preparations are summarized in Table 2 . The $\mathrm{M}_{\mathrm{w}}$ of LCC-C-CR (19870 g/mol) was higher than that of LCC-L-CR $(9700 \mathrm{~g} / \mathrm{mol})$. A similar trend was observed for $M_{n}$, with the values in LCC-C-CR and LCC-L-CR were $9800 \mathrm{~g} / \mathrm{mol}$ and $6570 \mathrm{~g} / \mathrm{mol}$, respectively. Meanwhile, the Lignin-CR preparation showed
TABLE 2 | The molecular weight $(\mathrm{g} / \mathrm{mol})$ and polydispersity of LCC-C-CR, LCC-L-CR and Lignin-CR.

\begin{tabular}{lccc}
\hline & $\mathbf{M}_{\mathbf{w}}{ }^{\mathbf{b}}$ & $\mathbf{M}_{\mathbf{n}}{ }^{\mathbf{b}}$ & Polydispersity $^{\mathbf{c}}$ \\
\hline LCC-C-CR $^{\text {a }}$ & 19870 & 9800 & 2.0 \\
LCC-L-CR $^{\text {a }}$ & 9700 & 6570 & 1.5 \\
Lignin-CR $^{a}$ & 8820 & 4910 & 1.8 \\
\hline
\end{tabular}

a LCC-C-CR, carbohydrate-rich LCC from WE-CR-TL; LCC-L-CR, lignin-rich LCC from WE-CR-TL; Lignin-CR, lignin from WE-CR-TL. ${ }^{b} M_{w}$, weight-average of molecular weight; $M_{n}$, number-average of molecular weight. ${ }^{c}$ Polydispersity: $M_{w} / M_{n}$.

lowest value of $M_{w}(8820 \mathrm{~g} / \mathrm{mol})$ and $M_{n}(4910 \mathrm{~g} / \mathrm{mol})$. The higher molecular weight identified in LCC-C-CR preparation may be due to the following two reasons: (1) the $\mathrm{M}_{\mathrm{w}}$ of LCCC-CR is indeed higher than that of LCC-L-CR; (2) the higher content of carbohydrate linked to lignin in LCC-C-CR alters the hydrodynamic volume of lignin, leading to the increase of apparent molar mass of lignin in GPC measurements (Sun et al., 2012). Moreover, LCC-C-CR, LCC-L-CR, and Lignin-CR exhibited narrow molecular weight distribution with relative polydispersity of $2.0,1.5$, and 1.8 .

\section{Structural Characterization of LCC and Lignin Preparations}

To obtain more insights on the actual chemical structures in LCC and lignin preparations, the advanced spectroscopy of NMR with ${ }^{13} \mathrm{C}$ NMR and 2D-HSQC were used. The quantitative ${ }^{13} \mathrm{C}$ NMR spectra of both LCC preparations are shown in Supplementary Figure 1, and all signals in spectra were assigned according to previous studies (Huang et al., 2019; Dong et al., 2020; Shen et al., 2020). As demonstrated, the abundant signals in 153103 ppm region were attributed to the syringyl units (S) and guaiacyl units $(G)$ in LCC. In $90-50$ ppm region, the signals were mainly from the substructures $(\beta-\mathrm{O}-4$ and $\beta-5)$ and carbohydrate. In addition, the signals that could be readily detected in 10290 ppm were also attributed to the carbohydrate (Supplementary Figure 1). Unfortunately, the signals of lignin-carbohydrate linkages in LCC overlap with the carbohydrate signals from 102 to 90 ppm and thus cannot be resolved using this method (Balakshin et al., 2007).

To overcome the issues of overlapping signals between lignincarbohydrate linkages and carbohydrate in ${ }^{13} \mathrm{C}$ NMR, the LCC 

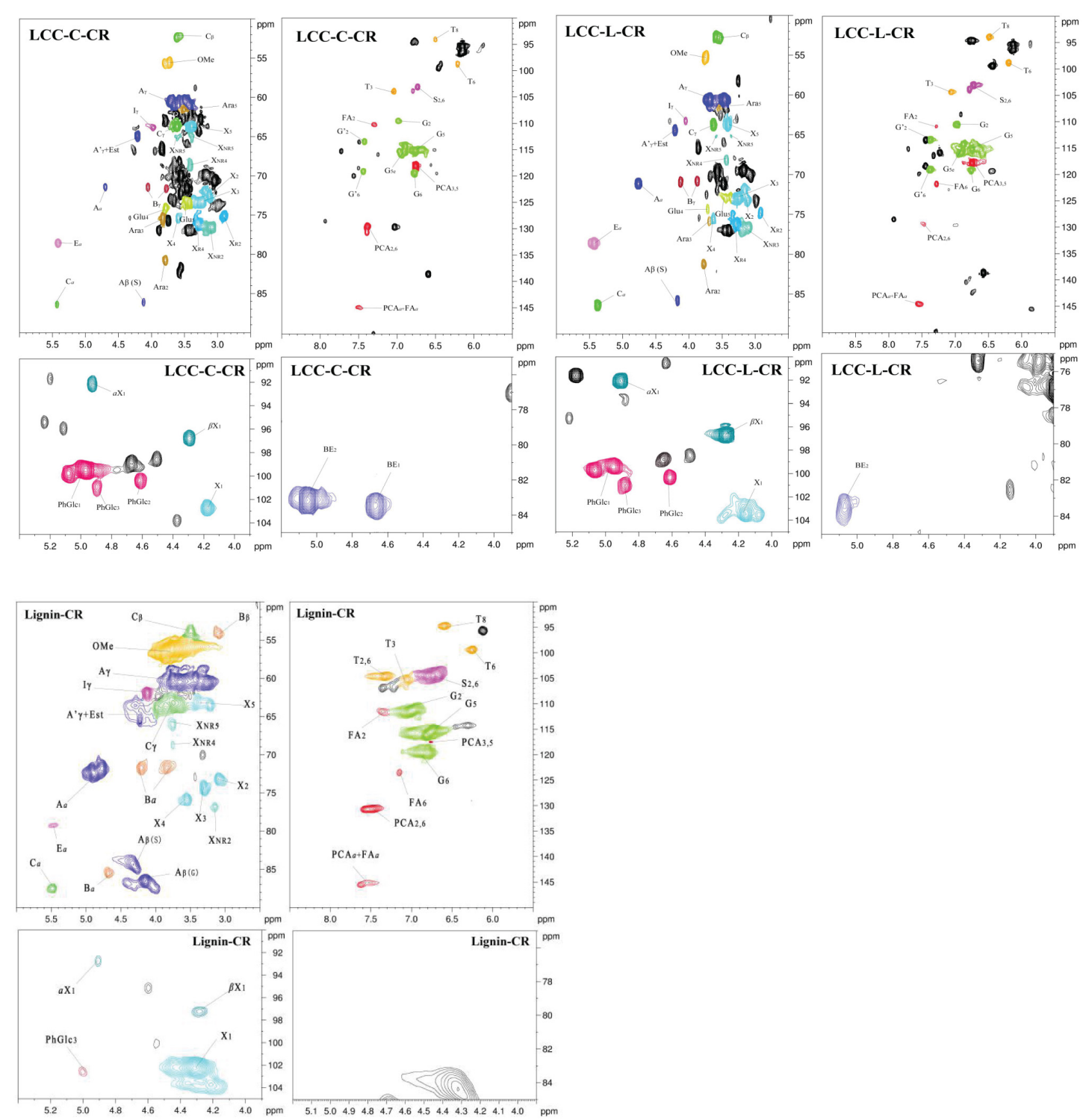

FIGURE 1 | 2D-HSQC NMR spectra of LCC-C-CR, LCC-L-CR, and Lignin-CR samples.

and lignin preparations were further analyzed using $2 \mathrm{D}-\mathrm{HSQC}$ NMR. The obtained spectra are shown in Figure 1. The main cross-signal assignments of the substructure and linkages in 2D-HSQC NMR spectra are summarized in Table 3, and their structures are graphically depicted in Figure 2. All signals from 2D-HSQC NMR spectra were assigned according to previous studies (Huang et al., 2019; Dong et al., 2020; Shen et al., 2020).

In the side-chain regions $\left(\delta_{\mathrm{C}} / \delta_{\mathrm{H}} 90-50 / 6.0-2.5\right)$ of LCC and lignin spectra, both the substructures of $\beta-\mathrm{O}-4$ (A) and resinols $(\beta-5, C)$ can be easily determined on the basis of $\mathrm{C}_{\alpha}-\mathrm{H}_{\alpha}$ signals at $\delta_{\mathrm{C}} / \delta_{\mathrm{H}} 71.8 / 4.87$ and $\delta_{\mathrm{C}} / \delta_{\mathrm{H}} 86.8 / 5.49$, respectively. In addition, the erythro forms of syringyl (S)-type $\beta$-O-4 substructures was identified at $\delta_{C} / \delta_{\mathrm{H}} 86.1 / 4.11\left(\mathrm{C}_{\beta}-\mathrm{H}_{\beta}\right.$ correlations) in LCC-C-CR and LCC-L-CR spectra, indicating that substructure A could be linked to $\mathrm{S}$ units in the lignin unit of LCCs. Meanwhile, guaiacyl
(G)-type $\beta$-O-4 substructures $\left(\mathrm{C}_{\beta}-\mathrm{H}_{\beta}\right.$ correlations at $\delta_{\mathrm{C}} / \delta_{\mathrm{H}}$ 83.9/4.30) was also identified in Lignin-CR spectra, indicating that both guaiacyl and syringyl units could be linked to $\beta-\mathrm{O}-4$ in the lignin. The identification of $\beta-\mathrm{O}-4$ and $\beta-5$ substructures is not beyond expectation since they are commonly shared by the LCCs/lignins from hardwood (Jiang et al., 2019). Our aforementioned results suggest that both LCC-C-CR and LCCL-CR are composed of similar chemical substructures (Figure 1). To further delineate structural differences among the LCC and lignin preparations, the quantification of lignin substructures was determined (Table 4). We found that Lignin-CR showed highest amount of each substructure, with 34.1/100 Ar for $\beta-\mathrm{O}-4$, 16.5/100 Ar for $\beta-5$ and 16.1/100 Ar for $a, \beta$-diaryl ether. The $\beta$-O4 (10.2/100 Ar), $\beta-5$ (8.7/100 Ar), and $a, \beta$-diaryl ether (12.7/100 Ar) substructures in LCC-C-CR were less abundant than those 
TABLE 3 | Main cross-signal assignments of substructure and linkages in 2D-HSQC NMR spectra.

\begin{tabular}{|c|c|c|}
\hline Labels & $\delta_{\mathrm{C}} / \delta_{\mathrm{H}}$ & Assignment \\
\hline \multicolumn{3}{|c|}{ Lignin structure } \\
\hline $\mathrm{C}_{\beta}$ & $53.1 / 3.49$ & $\begin{array}{l}\mathrm{C}_{\beta}-\mathrm{H}_{\beta} \text { in phenylcoumaran } \\
\text { substructures }(\mathrm{C})\end{array}$ \\
\hline$-\mathrm{OCH}_{3}$ & $55.9 / 3.73$ & $\mathrm{C}-\mathrm{H}$ in methoxyls \\
\hline$A_{\gamma}$ & $59.6-60.8 / 3.37-3.72$ & $\mathrm{C}_{\gamma}-\mathrm{H}_{\gamma}$ in $\beta-\mathrm{O}-4$ substructures (A) \\
\hline $\mathrm{A}^{\prime} \gamma$ & $63.6 / 4.36$ & $\begin{array}{l}\mathrm{C}_{\gamma}-\mathrm{H}_{\gamma} \text { in } \gamma \text {-acylated } \beta-\mathrm{O}-4 \\
\text { substructures }\left(\mathrm{A}^{\prime}\right)\end{array}$ \\
\hline$E_{a}$ & $79.5 / 5.45$ & $\mathrm{C}_{a}-\mathrm{H}_{a}$ in $a, \beta$-diaryl ether (E) \\
\hline$A_{\beta(S)}$ & $86.0 / 4.11$ & $\begin{array}{l}\mathrm{C}_{\beta}-\mathrm{H}_{\beta} \text { in } \beta-\mathrm{O}-4 \text { substructures linked to } \\
\text { a S unit }(A)\end{array}$ \\
\hline $\mathrm{C}_{a}$ & $86.8 / 5.49$ & $\begin{array}{l}\mathrm{C}_{a}-\mathrm{H}_{a} \text { in phenylcoumaran } \\
\text { substructures }(\mathrm{C})\end{array}$ \\
\hline $\mathrm{T}_{8}$ & $94.2 / 6.59$ & $\mathrm{C}_{8}-\mathrm{H}_{8}$ in tricin $(T)$ \\
\hline $\mathrm{T}_{6}$ & $98.8 / 6.27$ & $\mathrm{C}_{2,6}-\mathrm{H}_{2,6}$ in tricin $(\mathrm{T})$ \\
\hline $\mathrm{T}_{3}$ & $106.1 / 7.07$ & $\mathrm{C}_{3}-\mathrm{H}_{3}$ in tricin $(\mathrm{T})$ \\
\hline $\mathrm{S}_{2,6}$ & $104.1 / 6.74$ & $\mathrm{C}_{2,6}-\mathrm{H}_{2,6}$ in etherified syringyl units $(\mathrm{S})$ \\
\hline $\mathrm{G}_{2}$ & $111.0 / 7.01$ & $\mathrm{C}_{2}-\mathrm{H}_{2}$ in guaiacyl units $(\mathrm{G})$ \\
\hline $\mathrm{FA}_{2}$ & $111.1 / 7.34$ & $\mathrm{C}_{2}-\mathrm{H}_{2}$ in ferulate (FA) \\
\hline $\mathrm{G}_{5}$ & $114.4 / 6.73$ & $\mathrm{C}_{5}-\mathrm{H}_{5}$ in guaiacyl units $(\mathrm{G})$ \\
\hline $\mathrm{PCA}_{3,5}$ & $116.2 / 6.77$ & $\begin{array}{l}\mathrm{C}_{3}-\mathrm{H}_{3} \text { and } \mathrm{C}_{5}-\mathrm{H}_{5} \text { in } p \text {-coumarate } \\
\text { (PCA) }\end{array}$ \\
\hline $\mathrm{G}_{6}$ & $119.0 / 6.82$ & $\mathrm{C}_{6}-\mathrm{H}_{6}$ in guaiacyl units $(\mathrm{G})$ \\
\hline $\mathrm{PCA}_{2,6}$ & $130.1 / 7.48$ & $\mathrm{C}_{2,6}-\mathrm{H}_{2,6}$ in $p$-hydroxyphenyl units $(\mathrm{H})$ \\
\hline $\mathrm{PCA}_{a}$ and $\mathrm{FA}_{a}$ & $144.7 / 7.46$ & $\begin{array}{l}\mathrm{C}_{a}-\mathrm{H}_{a} \text { in } p \text {-coumarate }(\mathrm{PCA}) \text { and } \\
\text { ferulate (FA) }\end{array}$ \\
\hline \multicolumn{3}{|c|}{ Associated carbohydrate and LCCs linkages } \\
\hline $\operatorname{Ara}_{5}$ & $61.9 / 3.52$ & $\mathrm{C}_{5}-\mathrm{H}_{5}$ in $\mathrm{a}-(1 \rightarrow 4)-\mathrm{L}$-arabinofuranoside \\
\hline$x_{5}$ & $62.6 / 3.40$ & $\mathrm{C}_{5}-\mathrm{H}_{5}$ in $\beta$-(1 $\left.\rightarrow 4\right)$-D-xylopyranoside \\
\hline $\mathrm{X}_{N R 5}$ & $65.5 / 3.01,3.65$ & $\begin{array}{l}\mathrm{C}_{5}-\mathrm{H}_{5} \text { in } \beta \text { - }(1 \rightarrow 4) \text {-D-xylopyranoside } \\
\text { with non-ducing end }\end{array}$ \\
\hline $\mathrm{X}_{N R 4}$ & $69.5 / 3.24$ & $\begin{array}{l}\left.\mathrm{C}_{4}-\mathrm{H}_{4} \text { in } \beta \text {-(1 } \rightarrow 4\right) \text {-D-xylopyranoside } \\
\text { with non-ducing end }\end{array}$ \\
\hline$x_{2}$ & $72.5 / 3.02$ & $\mathrm{C}_{2}-\mathrm{H}_{2}$ in $\beta-(1 \rightarrow 4)-D-x y l o p y r a n o s i d e$ \\
\hline$X_{3}$ & $73.7 / 3.22$ & $\mathrm{C}_{3}-\mathrm{H}_{3}$ in $\beta-(1 \rightarrow 4)-\mathrm{D}$-xylopyranoside \\
\hline $\mathrm{X}_{4}$ & $75.4 / 3.60$ & $\mathrm{C}_{4}-\mathrm{H}_{4}$ in $\beta$-(1 $\left.\rightarrow 4\right)$-D-xylopyranoside \\
\hline $\mathrm{Ara}_{3}$ & $77.1 / 3.72$ & $\mathrm{C}_{3}-\mathrm{H}_{3}$ in $\mathrm{a}-(1 \rightarrow 4)$ - $\mathrm{L}$-arabinofuranoside \\
\hline $\mathrm{Ara}_{2}$ & $81.6 / 3.89$ & $\mathrm{C}_{3}-\mathrm{H}_{3}$ in $\mathrm{a}-(1 \rightarrow 4)$ - $\mathrm{L}$-arabinofuranoside \\
\hline$a X_{1}$ & $92.0 / 4.88$ & $\mathrm{C}_{1}-\mathrm{H}_{1}$ in $(1 \rightarrow 4)-\mathrm{a}-\mathrm{D}$-xylopyranoside \\
\hline$\beta X_{1}$ & $97.4 / 4.26$ & $\mathrm{C}_{1}-\mathrm{H}_{1}$ in $(1 \rightarrow 4)-\beta$-D-xylopyranoside \\
\hline$X_{1}$ & $103.2 / 4.21$ & $\mathrm{C}_{1}-\mathrm{H}_{1}$ in $\beta$-(1 $\left.\rightarrow 4\right)$-D-xylopyranoside \\
\hline$E s t+A^{\prime} \gamma$ & $65-62 / 4.5-4.0$ & $\gamma$-ester and $\mathrm{A}^{\prime} \gamma$ in LCC \\
\hline $\mathrm{BE}_{1}$ & $81.4 / 4.64$ & $\begin{array}{l}\text { Benzyl ether (in primary } \mathrm{OH} \text { of } \\
\text { carbohydrate) in LCC }\end{array}$ \\
\hline $\mathrm{BE}_{2}$ & $81.2 / 5.06$ & $\begin{array}{l}\text { Benzyl ether (in secondary } \mathrm{OH} \text { of } \\
\text { carbohydrate) in LCC }\end{array}$ \\
\hline PhGlc1 & $100.1 / 5.09$ & Phenyl glycoside-1 in LCC \\
\hline PhGlc2 & $100.9 / 4.63$ & Phenyl glycoside-2 in LCC \\
\hline PhGlc3 & $101.9 / 4.92$ & Phenyl glycoside-3 in LCC \\
\hline
\end{tabular}

in LCC-L-CR (15.9/100 Ar for $\beta$-O-4, 10.5/100 $\mathrm{Ar}$ for $\beta-5$ and $14.2 / 100 \mathrm{Ar}$ for $a, \beta$-diaryl ether substructures). According to the published research findings, the amount of $\beta$-O-4 ranges from 21/100 Ar to 100/100 Ar in LCC preparations from bamboo (Dong et al., 2020), Ginkgo (Jiang et al., 2019), and Arundo donax
Linn (You et al., 2015). The lower amount of $\beta$-O-4 substructure in LCC preparations from C. retusus tender leaf might be due to insufficient lignification, since the growth age is $1-3$ months.

In the aromatic regions $\left(\delta_{\mathrm{C}} / \delta_{\mathrm{H}} 160-90 / 8.0-6.0\right)$ of LCC-C-CR, LCC-L-CR and Lignin-CR spectra, the major correlation signals of syringyl unit (S) and guaiacyl unit (G) of lignin were identified. The signal appeared at $\delta_{\mathrm{C}} / \delta_{\mathrm{H}} 104.1 / 6.72$ was attributed to the $\mathrm{C}_{2,6}-\mathrm{H}_{2,6}$ correlations of $\mathrm{S}$ unit. For the $\mathrm{G}$ unit, the correlations of $\mathrm{C}_{2}-\mathrm{H}_{2}, \mathrm{C}_{5-} \mathrm{H}_{5}$, and $\mathrm{C}_{6-} \mathrm{H}_{6}$ were observed by the signals at $\delta_{\mathrm{C}} / \delta_{\mathrm{H}}$ $111.0 / 7.01,114.4 / 6.73$, and 119.0/6.82, respectively. In LCC-CCR, LCC-L-CR, and Lignin-CR, the respective S/G ratio was $0.63,0.44$, and 0.39 , and these are lower than the $S / G$ ratio of LCCs from Arundo donax Linn (0.65) and poplar (1.62) (Yuan et al., 2011; You et al., 2015). Taken together, the differences in the amount of substructures and $S / G$ value between current and previous studies highlight that growth age may influence not only the contents of aryl ether linkages but also the S/G ratio of LCC/lignin in different biomass (Jiang et al., 2019).

The prominent signals attributed to $p$-coumarate (PCA) and ferulate (FA) structures were also observed in LCC-C-CR, LCCL-CR and Lignin-CR, although they are typically undetectable in general woody biomass (Table 3). As pointed out by Jiang et al. (2019), both PCA and FA actively participate in the inchoate process of lignification. The FA provides the initiation sites for lignification in the cell wall, whereas monolignol conjugated PCA provides building bridge for lignin (Ralph, 2010). Therefore, the presence of the C-H correlations of PCA and FA emphasizes that C. retusus tender leaves used in this study are still in the process of lignification. This further supports our previous hypothesis regarding the impact of growth age on lignin chemical properties. It is noteworthy that the presence of PCA and FA structures also contribute to the antioxidant capability of LCC (Jiang et al., 2020a), suggesting the essential roles of PCA and FA in carrying out biological functions of LCC and lignin.

\section{Identification of Associated Carbohydrates and LCC Types in LCC Preparations}

In the 2D HSQC spectra, multiple types of signals of associated carbohydrates in LCCs were also detected, including the $\beta$-Dxylopyranoside units (X), glucopyranoside units (Glu), and arabinofuranoside units (Ara) (Jiang et al., 2019; Dong et al., 2020). The cross-peaks for correlations of $\mathrm{C}_{1}-\mathrm{H}_{1}, \mathrm{C}_{2}-\mathrm{H}_{2}, \mathrm{C}_{3}$ $\mathrm{H}_{3}, \mathrm{C}_{4}-\mathrm{H}_{4}$, and $\mathrm{C}_{5}-\mathrm{H}_{5}$ in $\mathrm{X}$ can be found at $\delta_{\mathrm{C}} / \delta_{\mathrm{H}} 103.2 / 4.19$, $72.5 / 3.03,73.7 / 3.22,75.6 / 3.63$, and $62.6 / 3.40$, respectively. In addition, the types of $a$-D-( $1 \rightarrow 4)$-xylopyranoside units $(a \mathrm{X})$ and $\beta$-D-( $(1 \rightarrow 4)$-xylopyranoside units $(\beta X)$, which can be differentiated by the $\mathrm{C}_{1}-\mathrm{H}_{1}$ correlations at $\delta_{\mathrm{C}} / \delta_{\mathrm{H}} 92.0 / 4.88$ and $\delta_{C} / \delta_{H} 97.0 / 4.26$, were present in both LCC-C-CR and LCC-LCR (You et al., 2015). Overall, the identification of associated carbohydrates in LCCs were in line with the results from our compositional analysis (Table 1).

The generally accepted lignin-carbohydrate linkages in LCC are benzyl ethers (BE), phenyl glycosides (PhGlc), and benzyl esters (Est) (Balakshin et al., 2007; Yuan et al., 2011). In Figure 1, the cross-peaks of PhGlc linkages were observed in the spectra 

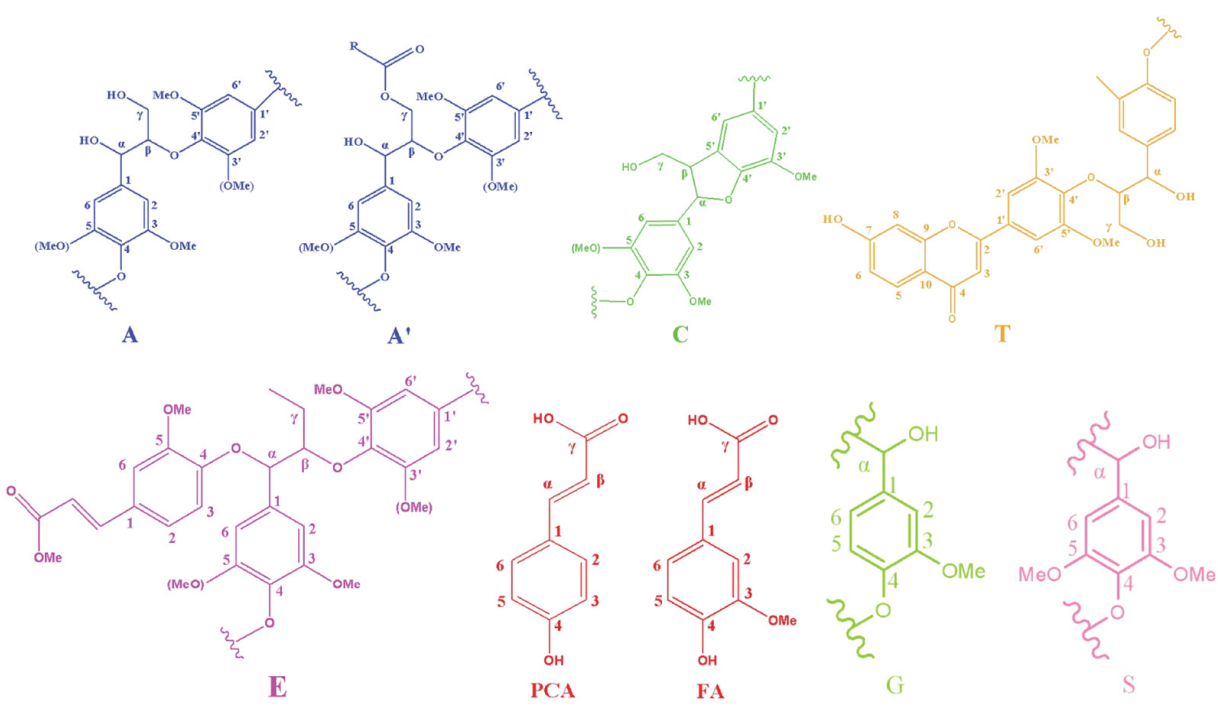<smiles>COc1cc([N+](=O)[O-])cc(C)c1OC</smiles>

phenyl glycoside (PhGlc)

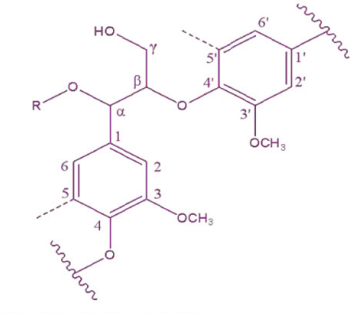

$\mathrm{C} 1: \mathrm{R}=\mathrm{C} 6$ in $\mathrm{Glc}, \mathrm{Man}, \mathrm{Gal}, \mathrm{C} 5$ in Ara
$\mathrm{C} 2 \mathrm{R}=\mathrm{C} 2$ or $\mathrm{C} 3$ in $\mathrm{Xyl}, \mathrm{Glc}, \mathrm{Man}, \mathrm{Gal}, \mathrm{Ara}$ benzyl ether (BE)

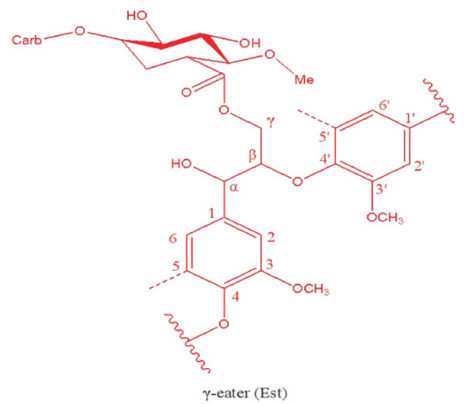

FIGURE 2 | Main structures identified in the LCC preparations.

TABLE 4 | The amount of lignin substructure and lignin-carbohydrate linkages in LCC-C-CR, LCC-L-CR, and Lignin-CR preparations (100 Ar).

\begin{tabular}{lccc}
\hline Characteristics & LCC-C-CR & LCC-L-CR & Lignin-CR \\
\hline Lignin interunit linkages & & & \\
$\beta$-O-4 aryl ethers (A) & 10.2 & 15.9 & 34.1 \\
phenylcoumarans, $\beta$-5 (C) & 8.7 & 10.5 & 16.5 \\
a, $\beta$-diaryl ether, a-O-4 (E) & 12.7 & 14.2 & 16.1 \\
S/G ratio & 0.63 & 0.44 & 0.39 \\
LCC linkages & & & \\
benzyl ether (BE) & 4.3 & 9.7 & 1 \\
phenyl glycoside (PhGlc) $_{\text {Est }}{ }^{\text {b }}$ & 10.5 & 8.3 & 1.1 \\
Total $^{c}$ & 6.3 & 5.9 & 12.5 \\
\end{tabular}

aCalculated based on 2D HQSC spectra data using the formula: $S / G=I_{103-108} / 6.4-7.0 /\left(I_{108}-114 / 6.9-7.3 / 2\right)$. bSum of LCCs $\gamma$-esters (Est) and $\gamma$-acylated $\beta-0-4$ aryl ether substructures. 'Sum of the amount of $B E, P h G / c$, and Est.

of both LCC-C-CR and LCC-L-CR. In the region of $\delta_{C} / \delta_{H} 105-$ 90/5.4-3.9, three kinds of PhGlc can be detected as indicated by the signals at $\delta_{C} / \delta_{H} 100.1 / 5.09$ (PhGlc1), 100.9/4.63 (PhGlc2), and 101.5/4.79 (PhGlc3). However, only PhGlc3 was detected in Lignin-CR. Based on the quantification analysis (Table 4), LCC-C-CR showed a slightly higher amount of PhGlc (10.5/100 Ar) than LCC-L-CR (8.3/100 Ar) and Lignin-CR (1.1/100 Ar). This may be due to the higher total contents of glucan and xylan $(52.0 \%)$ in LCC-C-CR, comparing to LCC-L-CR (29.8\%). As reported by Balakshin et al. (2011) and Yuan et al. (2011), the predominant types of carbohydrates that are involved in the formation of phenyl glycoside linkages are glucan and xylan. For BE linkages, LCC spectra revealed the signals at $\delta_{C} / \delta_{H}$ 83.4/4.63 (BE1) and $\delta_{C} / \delta_{H} 83.2 / 5.14$ (BE2), which are attributed to the $\mathrm{C} 1$-linkages between the a-position of lignin and primary $\mathrm{OH}$ groups of carbohydrates, and $\mathrm{C} 2$-linkages between the $a$-position of lignin and secondary $\mathrm{OH}$ groups of carbohydrates. As shown in Table 4, the amount of benzyl ether linkages in LCC-C-CR and LCC-L-CR were 4.3/100 $\mathrm{Ar}$ and 9.7/100 Ar, respectively. However, these signals were absent in Lignin-CR due to its high purity with only trace amount of carbohydrate. Generally, the benzyl ester linkage is observed by $a$-ester or $\gamma$-ester signal at $\delta_{C} / \delta_{H} 75 / 6.1$ and $\delta_{C} / \delta_{H}$ 65-62/4.04.5 (Jiang et al., 2020b). In this study, no signals from $a$-ester structures could be detected in LCC and lignin preparations. 
A

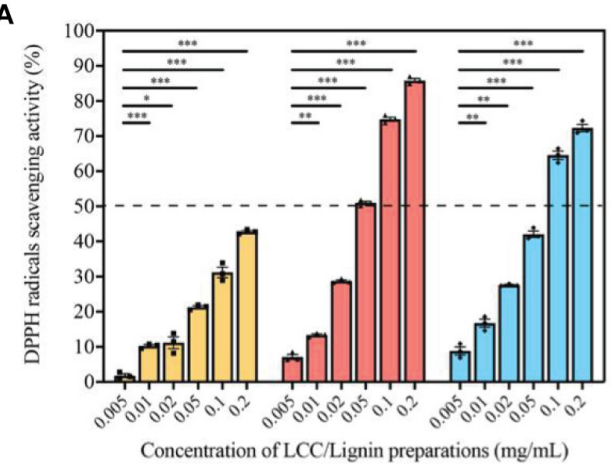

C

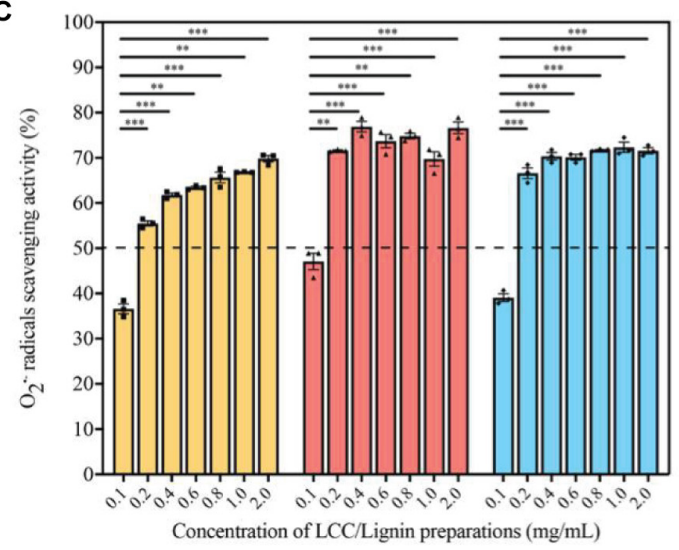

B

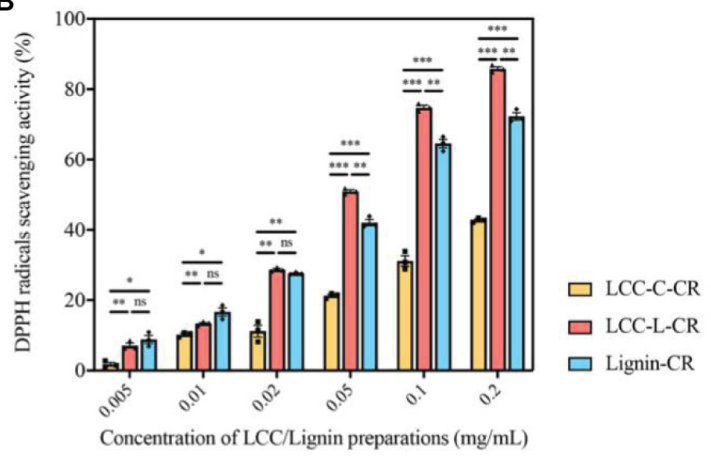

D

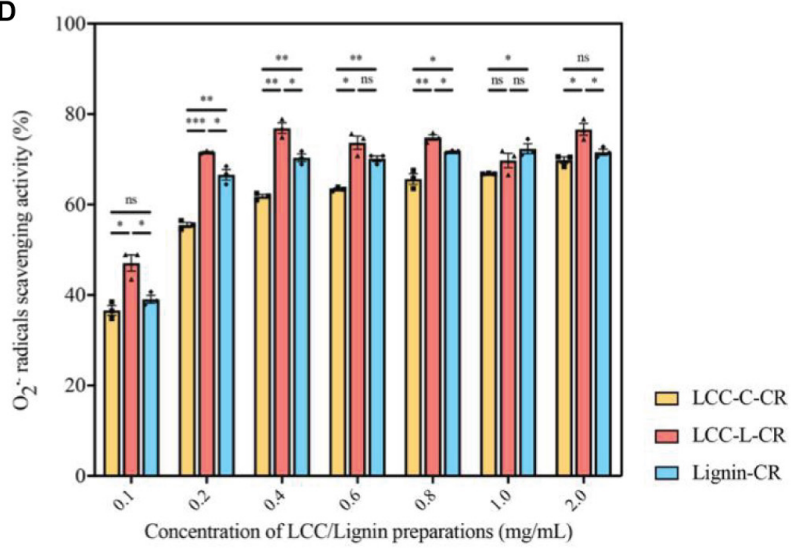

FIGURE 3 | The LCC and lignin preparations showed antioxidant activities. (A) The DPPH radicals scavenging activities of LCC and lignin preparations were increased dose-dependently. $n=3$ biological replicates. Each $n$ represents an independent preparation of antioxidant assay samples. Error bars represent S.E.M. Statistical analysis was performed using two-tailed unpaired Student's $t$-test. * denotes $p<0.05$, ** denotes $p<0.01$, and $* * *$ denotes $p<0.001$. (B) The LCC-L-CR elicited more potent scavenging capability than LCC-C-CR and Lignin-CR, especially when treated at higher concentrations. $n=3$ biological replicates. Each $n$ represents an independent preparation of antioxidant assay samples. Error bars represent S.E.M. Statistical analysis was performed using one-way ANOVA followed by post hoc Tukey's test. ns denotes no significant difference, ${ }^{*}$ denotes $p<0.05$, ${ }^{* *}$ denotes $p<0.01$, and *** denotes $p<0.001$. (C) The scavenging capabilities of $\mathrm{LCC}$ and lignin preparations toward $\mathrm{O}_{2}{ }^{\bullet-}$ were significantly enhanced when used at higher concentrations. $n=3$ biological replicates. Each $n$ represents an independent preparation of antioxidant assay samples. Error bars represent S.E.M. Statistical analysis was performed using two-tailed unpaired Student's $t$-test. ${ }^{* *}$ denotes $p<0.01$ and ${ }^{* * *}$ denotes $p<0.001$. (D) The $\mathrm{O}_{2}{ }^{\bullet-}$ radical scavenging activity of LCC-L-CR was significantly higher than that of LCC-C-CR and Lignin-CR, except for treating at 0.6 and $1.0 \mathrm{mg} / \mathrm{mL} . n=3$ biological replicates. Each $n$ represents an independent preparation of antioxidant assay samples. Error bars represent S.E.M. Statistical analysis was performed using one-way ANOVA followed by post hoc Tukey's test. ns denotes no significant difference, ${ }^{*}$ denotes $p<0.05,{ }^{* *}$ denotes $p<0.01$ and $* * *$ denotes $p<0.001$.

This is similar to what was reported in Balakshin et al. (2011). Although $\gamma$-ester showed the signal at $\delta_{C} / \delta_{H} 64.5 / 4.19$ in LCCC-CR and LCC-L-CR, this could be attributed to the signal of $\gamma$-acylated lignin moiety $\left(\mathrm{A}^{\prime}\right)$. As pointed out by Balakshin et al. (2011), the signal of LCC $\gamma$-esters can overlap with the signal from $\gamma$-acetyl of substructures $A\left(A^{\prime}\right)$. Those two overlapping signals could be distinguished using higher powered NMRs. The calculated $\gamma$-esters value in our LCC samples is the sum of benzyl ester in LCC and acetyl $\gamma$-esters in lignin. As demonstrated in Table 4, the amount $\gamma$-ester was more abundant in Lignin-CR (12.5/100 Ar), when compared to LCCC-CR (6.3/100 Ar) and LCC-L-CR (5.9/100 Ar). Regardless the amount of $\gamma$-ester, we found that PhGlc was the predominant linkage in LCC-C-CR (49.8\%), while BE was the predominant linkage in LCC-L-CR (40.1\%). These findings are in accordance to previous report, in which You et al. (2015) demonstrated that carbohydrate-rich LCC and lignin-rich LCC derived from
Arundo donax Linn were enriched in PhGlc (84.8\%) and BE (96.6\%) linkages, respectively.

\section{Antioxidant Activity Analysis of LCC and Lignin Preparations}

Both lignin and carbohydrate have been implicated in scavenging free radicals in vitro and in vivo due to their antioxidant activities (Wang L. et al., 2019). We then examined if LCCs from C. retusus tender leaf exert similar antioxidant functions. In addition, the carbohydrate-free lignin preparation (Lignin-CR) was also included. The 2,2-diphenyl-1-picrylhydrazyl (DPPH) radicals and superoxide anion $\left(\mathrm{O}_{2}{ }^{\bullet-}\right)$ radicals were used as the reference substances to evaluate their scavenging capabilities in vitro.

As demonstrated in Figure $\mathbf{3 A}$, the scavenging capabilities toward DPPH radicals were significantly enhanced when the treatment concentrations of LCC-C-CR, LCC-L-CR and 

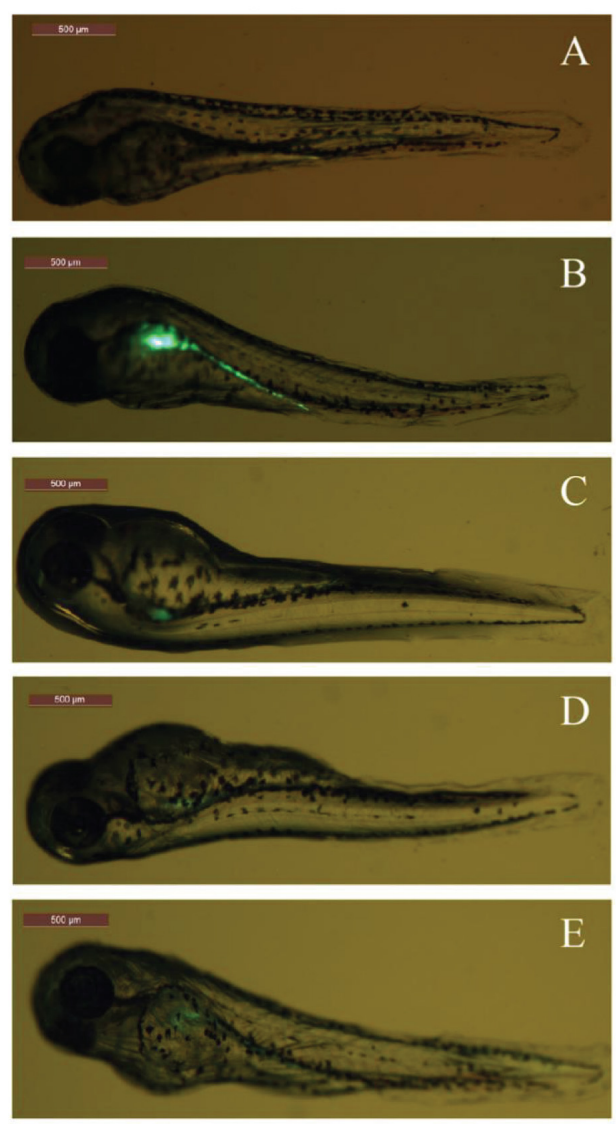

F

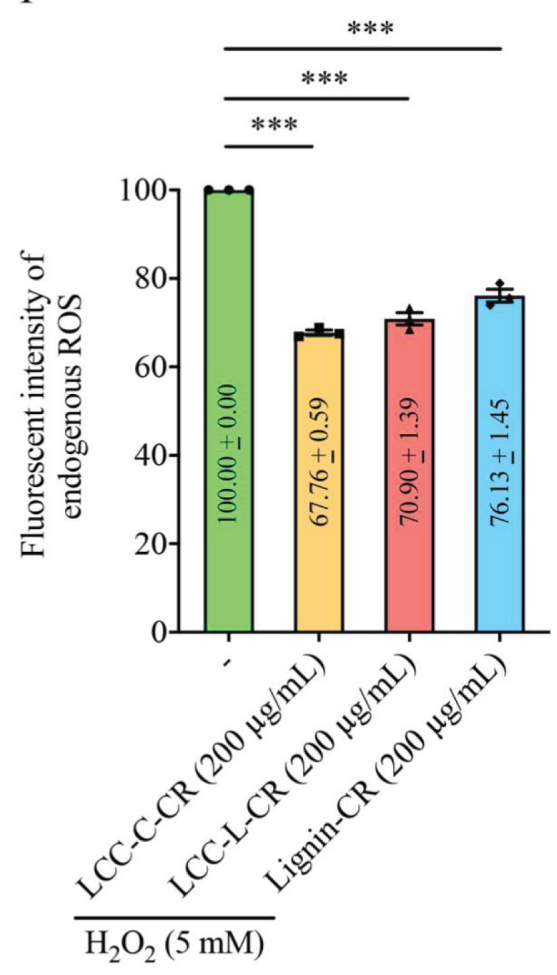

FIGURE 4 | Both LCC and lignin preparations scavenged ROS production in vivo. The level of ROS production in zebrafish model was reflected by the intensity of green fluorescent signal in non-treatment (A), $\mathrm{H}_{2} \mathrm{O}_{2}$-treated (B), LCC-C-CR-treated (C), LCC-L-CR-treated (D), and Lignin-CR-treated (E) groups. Scale bars: $500 \mu \mathrm{m} . n=3$ biological replicates. Each $n$ represents an independent preparation of fluorescence imaging samples. Only representative images were shown. (F) Quantification of the green fluorescent signal in panel (B-E). At least four zebrafish were used in $\mathrm{H}_{2} \mathrm{O}_{2}$, LCCs or lignin-treated group from an independent experiment. Error bars represent S.E.M. Statistical analysis was performed using two-tailed unpaired Student's $t$-test. ${ }^{* * *}$ denotes $p<0.001$.

Lignin-CR were dose-dependently increased. The scavenging activity of LCC-L-CR was significantly stronger than that of LCC-C-CR and Lignin-CR, especially when used at higher concentrations (Figure 3B). Meanwhile, LCC-L-CR showed an $\mathrm{IC}_{50}$ concentration (the concentration for quenching $50 \%$ of the initial radical) of $0.05 \mathrm{mg} / \mathrm{ml}$, which was lower than that of LCC-C-CR $(>0.2 \mathrm{mg} / \mathrm{mL})$ and Lignin-CR $(0.06 \mathrm{mg} / \mathrm{ml})$ (Figure 3A). As for $\mathrm{O}_{2}{ }^{\bullet-}$ radicals, the scavenging capabilities were also significantly upregulated upon treatment of higher concentrations of LCC-C-CR, LCC-L-CR, and Lignin-CR (Figure 3C). Compared to LCC-C-CR and Lignin-CR, the scavenging activity of LCC-L-CR was significantly stronger, except for treating at 0.6 and $1.0 \mathrm{mg} / \mathrm{mL}$ (Figure 3D). The $\mathrm{IC}_{50}$ value for $\mathrm{O}_{2}{ }^{--}$radicals scavenging activity in LCC-L-CR treatment group was $0.11 \mathrm{mg} / \mathrm{mL}$, which was lower than the $\mathrm{IC}_{50}$ in LCC-C-CR $(0.19 \mathrm{mg} / \mathrm{mL})$ and Lignin-CR $(0.14 \mathrm{mg} / \mathrm{mL})$ treatment groups (Figure $3 \mathrm{C}$ ). Taken together, these results indicate that the antioxidant activity of neat lignin could be further potentiated when a certain amount of carbohydrate was structurally incorporated. This is in agreement with a previous study reported by Zhang et al. (2018). In our obtained LCC preparations, both of them exhibit free radicals scavenging activities, while the scavenging capability of LCC-L-CR is higher than that of LCC-C-CR, especially toward DPPH radicals.

Together with chemical compositional data (Table 1), we found that LCC preparation with less amount of carbohydrates exhibited greater antioxidant potency than carbohydrate-rich LCC and neat lignin (Figure 3). However, in another study, Zhao et al. (2015) found that hemicellulose fractions with different monosaccharide composition and molecular weight distribution demonstrated superior antioxidant capacity than a lignin-rich fraction. The discrepancy in these findings might be attributed to the different amount of hydrogen bonds formed between polar groups in carbohydrates and free phenolic functionalities in lignin (Ugartondo et al., 2008). In the current study, the higher percentage of carbohydrate in LCC-C-CR could result in more hydrogen bonding and thus lead to decreased antioxidant potency.

We next exploited a zebrafish model to evaluate the antioxidant activities of our LCC and lignin preparations in vivo. The non-treatment group (normal zebrafish) exhibited undetectable green fluorescent signal (acquired using confocal 


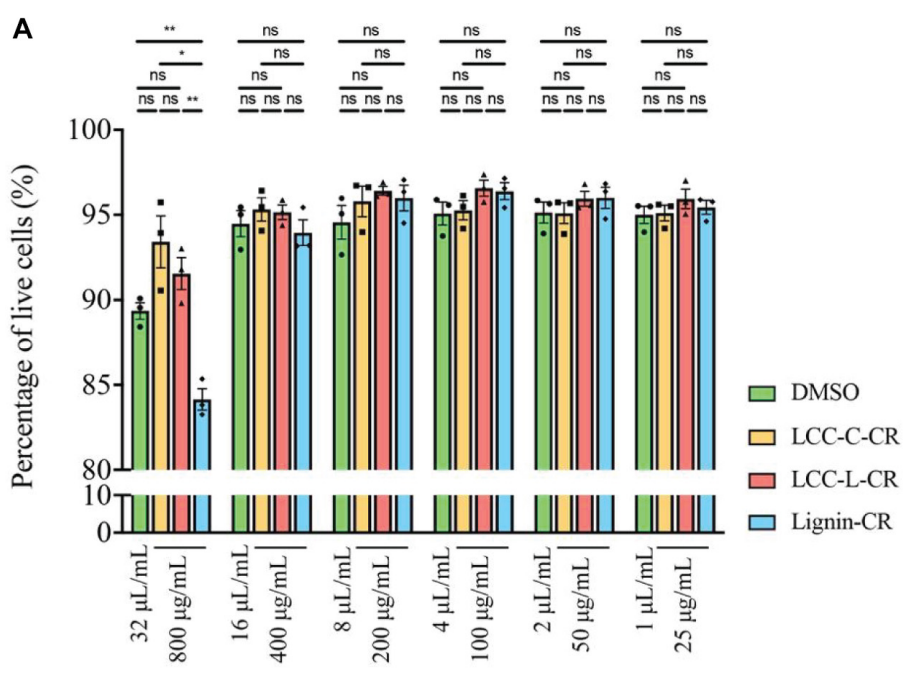

Concentration of LCC/Lignin preparations

B

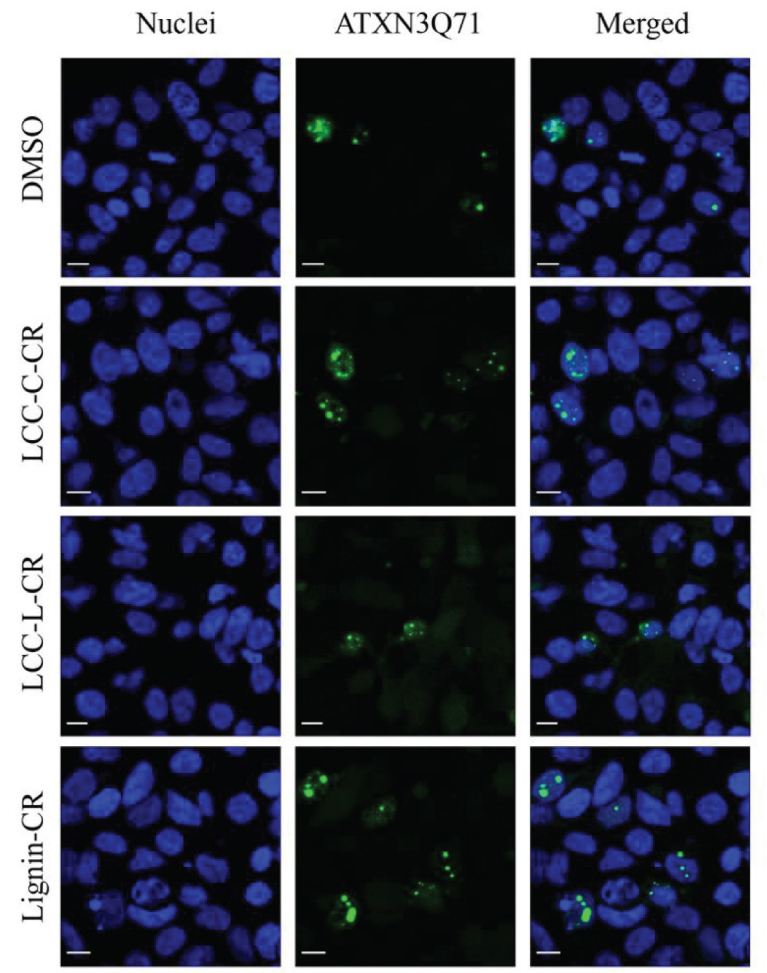

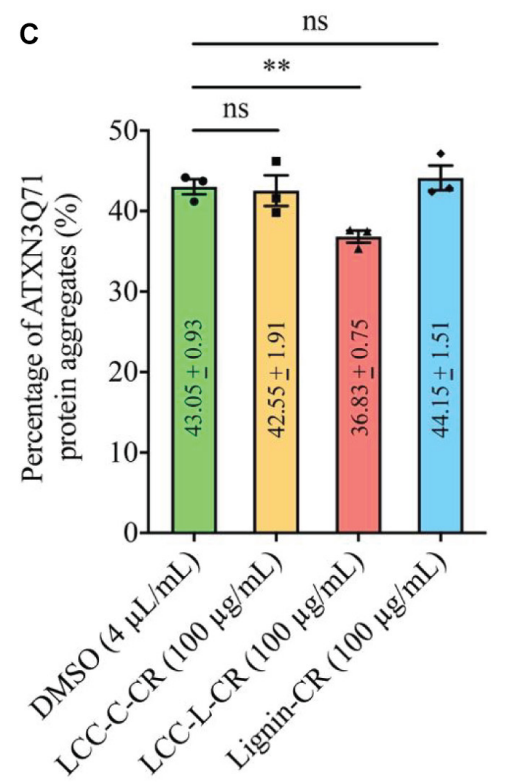

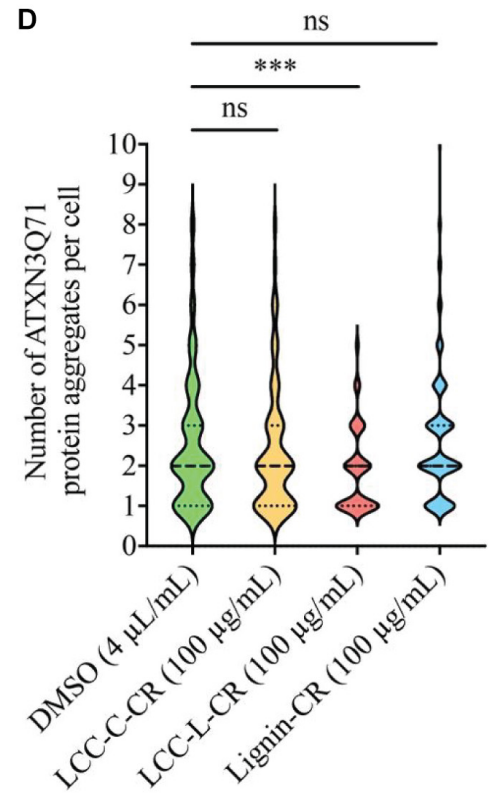

FIGURE $\mathbf{5}$ | The lignin-rich LCC preparation showed anti-protein aggregation activity toward polyQ protein aggregates. (A) Cytotoxicities of LCC and lignin preparations were tested on human neuroblastoma SK-N-MC cells. No significant difference on the percentage of live cells was detected between DMSO, LCC-C-CR, LCC-L-CR, and Lignin-CR groups when the treatment ranges from 25 to $400 \mu \mathrm{g} / \mathrm{mL}$. When treated at $800 \mu \mathrm{g} / \mathrm{mL}$, the percentage of live cells in Lignin-CR group was significantly reduced. $n=3$ biological replicates. Each $n$ represents an independent preparation of cytotoxicity sample. Error bars represent S.E.M. Statistical analysis was performed using one-way ANOVA followed by post hoc Tukey's test. ns denotes no significant difference, * denotes $p<0.05$ and $* *$ denotes $p<0.01$. (B) Treatment of LCC-L-CR, but not LCC-C-CR or Lignin-CR, suppressed the percentage of cells with ATXN3Q71 protein aggregates (green) in SK-N-MC cells. Cell nuclei (blue) were stained with DAPI. Scale bars: $50 \mu \mathrm{m} . n=3$ biological replicates. Each $n$ represents an independent preparation of fluorescence imaging samples. Only representative images were shown. (C) Quantification of the percentage of cells with ATXN3Q71 protein aggregates in panel (B). At least 85 of ATXN3Q71-transfected cells were counted in DMSO, LCCs or lignin-treated group from an independent experiment. Error bars represent S.E.M. Statistical analysis was performed using two-tailed unpaired Student's $t$-test. ns denotes no significant difference and ${ }^{* *}$ denotes $p<0.01$. (D) Quantification of the number of ATXN3Q71 protein aggregates per cell in panel (B). At least 35 cells with the formation of ATXNQ71 protein aggregates were counted in DMSO, LCCs or lignin-treated group from an independent experiment. Dash lines indicate median, while dotted lines indicate 25th and 75th quartiles. Statistical analysis was performed using Mann-Whitney $U$ test. ns denotes no significant difference and ${ }^{* * *}$ denotes $p<0.001$. 
laser scanning microscopy) (Figure 4A). Once stimulated with $\mathrm{H}_{2} \mathrm{O}_{2}$, the endogenous ROS (green fluorescent signal) was generated and concentrated in the yolk sac and its extension in zebrafish body (Figure 4B). Intriguingly, when the fishes were treated with either LCC-C-CR (Figure 4C), LCC-L-CR (Figure 4D) or Lignin-CR (Figure 4E) prior to $\mathrm{H}_{2} \mathrm{O}_{2}$ stimulation, the fluorescent intensity was significantly suppressed (Figure 4F). It can therefore be concluded that both the isolated LCC and lignin preparations possess in vivo antioxidant activity to scavenge the production of endogenous ROS.

\section{Effect of LCC and Lignin Preparations on ATXN3Q71 Protein Aggregation}

It has been previously reported that accumulation of oxidative species correlates with polyQ disease pathologies, and inhibition of oxidative stress attenuates the formation of polyQ protein aggregates and suppresses polyQ-induced cytotoxicities (Essa et al., 2019). Chang et al. (2014) demonstrated that geniposide, genipin and crocin from Gardenia jasminoides inhibit intracellular aggregation of polyQ protein via lowering the production of ROS in neuronal cells, suggesting an antiprotein aggregation activity of antioxidants from natural product. Given their antioxidant capabilities, we next tested if our LCC and lignin preparations would elicit any effect on modifying polyQ protein aggregation. A polyQ disease cell model was established with the overexpression of SCA type3 (SCA3) disease protein ATXN3Q71 (Ataxin-3 protein harboring 71 repeats of glutamine) in a human neuroblastoma cell line SK-N-MC (Chen Z. S. et al., 2018; Chen et al., 2019). The percentage of cells with polyQ protein aggregates was used as readout to evaluate the protein aggregation-modulatory effects of LCCs and lignin.

The cytotoxicities of LCC and lignin preparations were first examined in SK-N-MC cells without expression of polyQ disease protein. As shown in Figure 5A, when treated at $800 \mu \mathrm{g} / \mathrm{mL}$, the Lignin-CR group demonstrated significant lowered percentage of live cells compared to vehicle control (DMSO), LCC-CCR and LCC-L-CR groups. Such reduction of cell viability was not observed when Lignin-CR was used ranging from 25 to $400 \mu \mathrm{g} / \mathrm{mL}$, indicating the neat lignin fraction was slightly toxic to SK-N-MC cells, especially when treated at higher concentration. There is no significant difference on the percentage of live cells between DMSO-treated and LCC-treated groups, suggesting that obtained LCCs have low cytotoxicities and good biocompatibilities with SK-N-MC cells (Figure 5A).

Based on our cytotoxicity results, the two LCC preparations were further tested on the ATXN3Q71-expressing SK-N-MC cells, with the aim to evaluating their capabilities in modulating polyQ protein aggregation. The fluorescent images were captured by confocal laser scanning microscopy to visualize the formation of polyQ protein aggregates (Adegbuyiro et al., 2017). As demonstrated in Figure 5B, overexpression of expanded ATXN3Q71 protein led to the formation of intracellular protein aggregates (green fluorescent signal). We found that treatment with $100 \mu \mathrm{g} / \mathrm{mL}$ LCC-L-CR, but not LCC-C-CR or Lignin$\mathrm{CR}$, effectively suppressed the polyQ protein aggregation in ATXN3Q71-expressing cells (Figure 5B). The corresponding statistics (Figure 5C) showed that the percentage of cells with ATXN3Q71 protein aggregates was significantly downregulated from 43.1 to $36.8 \%$ upon treatment of LCC-L-CR, whereas no significant change was observed in the LCC-C-CR (42.6\%) and Lignin-CR (44.2\%) treatment groups. Meanwhile, the number of aggregated ATXN3Q71 protein (represented by green fluorescent dots) in each aggregates-containing cell was also determined. We found that treatment of LCC-L-CR, but not LCC-C-CR or Lignin-CR, significantly reduced the number of ATXN3Q71 protein aggregates per cell (Figure 5D). Moreover, treatment of LCC-C-CR, LCC-L-CR or Lignin-CR did not significantly alter the percentage of ATXN3Q71-transfected cells, suggesting that the suppression of ATXN3Q71 protein aggregates mediated by LCC-L-CR was not due to the perturbation of the transfection efficiency of pAcGFP-ATXN3Q71 plasmid in SK-N-MC cells (Supplementary Figure 2).

These results therefore suggest an anti-protein aggregation effect of LCC-L-CR toward ATXN3Q71 protein aggregates. The difference in the capabilities in suppressing ATXN3Q71 protein aggregation among LCC-L-CR, LCC-C-CR, and Lignin$\mathrm{CR}$ might be due to the higher antioxidant activity of LCC-L-CR (Figure 3). Overall, the lignin-rich LCC, but not carbohydrate-rich LCC and neat lignin, isolated from C. retusus tender leaves showed sufficient antioxidant and anti-protein aggregation activities.

\section{CONCLUSION}

In the current study, we managed to isolate lignin-rich LCC (LCC-L-CR), carbohydrate-rich LCC (LCC-C-CR), and lignin (Lignin-CR) from the hot-water extracted residual solids of C. retusus tender leaves. Both LCC preparations contain all types of LCC linkages but differ in abundance. The LCC-LCR showed superior antioxidant potency, which is believed to be the driving force behind its pronounced capability to suppress the intracellular aggregation of polyQ disease protein. In conclusion, this is the first report to highlight the antiprotein aggregation activity of a lignin-rich LCC isolated from C. retusus tender leaves, and this provides a new angle to investigate the LCC's biological functions. More importantly, our findings will contribute to the future studies of similar biological macromolecules in the biological and bioengineering fields.

\section{DATA AVAILABILITY STATEMENT}

All datasets presented in this study are included in the article/Supplementary Material.

\section{ETHICS STATEMENT}

The animal study was reviewed and approved by the Animal Ethics Committee of Nanjing Drum Tower Hospital, The Affiliated Hospital of Nanjing University Medical School (Permit number: 2019AE01018). 


\section{AUTHOR CONTRIBUTIONS}

WP and ZC: investigation. HC and CL: supervision. $\mathrm{CH}$ and LZ: writing - original draft. ZC and $\mathrm{CH}$ : writing - review and editing. All authors contributed to the article and approved the submitted version.

\section{FUNDING}

This work was supported by the Natural Science Foundation of Jiangsu Province (BK20180772), Open Foundation of Guangxi Key Laboratory of Clean Pulp \& Papermaking and Pollution Control (2019KF01), and Postgraduate Research and Practice

\section{REFERENCES}

Adegbuyiro, A., Sedighi, F., Pilkington, A. W. IV, Groover, S., and Legleiter, J. (2017). Proteins containing expanded polyglutamine tracts and neurodegenerative disease. Biochemistry 56, 1199-1217.

Arias, R. S., Techen, N., Rinehart, T. A., Olsen, R. T., Kirkbride, J. H., and Scheffler, B. E. (2011). Development of simple sequence repeat markers for Chionanthus retusus (Oleaceae) and effective discrimination of closely related taxa. HortScience 46, 23-29. doi: 10.21273/hortsci.46.1.23

Azhar, S., Henriksson, G., Theliander, H., and Lindström, M. E. (2015). Extraction of hemicelluloses from fiberized spruce wood. Carbohyd. Polym. 11, 19-24. doi: 10.1016/j.carbpol.2014.09.050

Balakshin, M. Y., Capanema, E. A., and Chang, H. M. (2007). MWL fraction with a high concentration of lignin-carbohydrate linkages: isolation and 2D NMR spectroscopic analysis. Holzforschung 61, 1-7. doi: 10.1515/hf.2007.001

Balakshin, M., Capanema, E., Gracz, H., Chang, H. M., and Jameel, H. (2011). Quantification of lignin-carbohydrate linkages with high-resolution NMR spectroscopy. Planta 233, 1097-1110. doi: 10.1007/s00425-011-1359-2

Bjoörkman, A. (1957). Lignin and lignin-carbohydrate complexes: extraction from wood meal with neutral solvents. Ind. Eng. Chem. 49, 1395-1398.

Chang, K. H., Chen, W. L., Wu, Y. R., Lin, T. H., Wu, Y. C., Chao, C. Y., et al. (2014). Aqueous extract of Gardenia jasminoides targeting oxidative stress to reduce polyQ aggregation in cell models of spinocerebellar ataxia 3. Neuropharmacology 81, 166-175. doi: 10.1016/j.neuropharm.2014.01.032

Chen, D., Gao, A., Ma, Z., Fei, D., Chang, Y., and Shen, C. (2018). In-depth study of rice husk torrefaction: characterization of solid, liquid and gaseous products, oxygen migration and energy yield. Bioresour. Technol. 253, 148-153. doi: 10.1016/j.biortech.2018.01.009

Chen, Z. S., Li, L., Peng, S., Chen, F. M., Zhang, Q., and An, Y. (2018). Planar cell polarity gene Fuz triggers apoptosis in neurodegenerative diseases. Embo. Rep. 19:e45419.

Chen, Z. S., Wong, A. K. Y., Cheng, T. C., Koon, A. C., and Chan, H. Y. E. (2019). FipoQ/FBXO33, a Cullin-1 based ubiquitin ligase complex component modulates ubiquitination and solubility of polyglutamine disease protein. J. Neurochem. 149, 781-798. doi: 10.1111/jnc.14669

Dong, H., Zheng, L., Yu, P., Jiang, Q., Wu, Y., Huang, C., et al. (2020). Characterization and application of lignin-carbohydrate complexes from lignocellulosic materials as antioxidants for scavenging in vitro and in vivo reactive oxygen species. ACS Sustain. Chem. Eng. 8, 256-266. doi: 10.1021/ acssuschemeng.9b05290

Essa, M. M., Moghadas, M., Ba-Omar, T., Qoronfleh, M. W., Guillemin, G. J., Manivasagam, T., et al. (2019). Protective effects of antioxidants in Huntington's disease: an extensive review. Neurotox. Res. 35, 739-774. doi: 10.1007/s12640018-9989-9

Fu, Y., Li, F., Ding, Y., Li, H. Y., Xiang, X. R., Ye, Q., et al. (2020). Polysaccharides from loquat (Eriobotrya japonica) leaves: impacts of extraction methods on their physicochemical characteristics and biological activities. Int. J. Biol. Macromo. 146, 508-517. doi: 10.1016/j.ijbiomac.2019.12.273

Gu, J., Pei, W., Tang, S., Yan, F., Peng, Z., Huang, C., et al. (2020). Procuring biologically active galactomannans from spent coffee ground (SCG) by
Innovation Program of Jiangsu Province (KYCX18_0048). In addition, the work was supported by the Postdoctoral Fellowship in Clinical Neurosciences program between The Chinese University of Hong Kong and University of Oxford (Nuffield Department of Clinical Neurosciences and Pembroke College) supported by the Lee Hysan Foundation for ZC.

\section{SUPPLEMENTARY MATERIAL}

The Supplementary Material for this article can be found online at: https://www.frontiersin.org/articles/10.3389/fbioe. 2020.573991/full\#supplementary-material

autohydrolysis and enzymatic hydrolysis. Int. J. Biol. Macromo. 149, 572-580. doi: 10.1016/j.ijbiomac.2020.01.281

Gurskaya, N. G., Fradkov, A. F., Pounkova, N. I., Staroverov, D. B., Bulina, M. E., Yanushevich, Y. G., et al. (2003). A colourless green fluorescent protein homologue from the non-fluorescent hydromedusa Aequorea coerulescens and its fluorescent mutants. Biochem. J. 373, 403-408. doi: 10.1042/bj20021966

He, J., Huang, C., Lai, C., Huang, C., Li, M., Pu, Y., et al. (2020). The effect of lignin degradation products on the generation of pseudo-lignin during dilute acid pretreatment. Ind. Crop. Prod. 146:112205. doi: 10.1016/j.indcrop.2020.112205

Hong, H., Koon, A. C., Chen, Z. S., Wei, Y., An, Y., Li, W., et al. (2019). AQAMAN, a bisamidine-based inhibitor of toxic protein inclusions in neurons, ameliorates cytotoxicity in polyglutamine disease models. J. Biol. Chem. 294, 2757-2770. doi: 10.1074/jbc.ra118.006307

Huang, C., He, J., Narron, R., Wang, Y., and Yong, Q. (2017). Characterization of kraft lignin fractions obtained by sequential ultrafiltration and their potential application as a biobased component in blends with polyethylene. ACS Sustain. Chem. Eng. 5, 11770-11779. doi: 10.1021/acssuschemeng.7b03415

Huang, C., Wang, X., Liang, C., Jiang, X., Yang, G., Xu, J., et al. (2019). A sustainable process for procuring biologically active fractions of highpurity xylooligosaccharides and water- soluble lignin from Moso bamboo prehydrolyzate. Biotechnol. Biofuels. 12:189.

Jiang, B., Chen, H., Zhao, H., Wu, W., and Jin, Y. (2020a). Structural features and antioxidant behavior of lignins successively extracted from ginkgo shells (Ginkgo biloba L). Int. J. Biol. Macromo. 163, 694-701

Jiang, B., Song, J., and Jin, Y. (2020b). A flavonoid monomer tricin in gramineous plants: metabolism, bio/chemosynthesis, biological properties, and toxicology. Food. Chem. 320:126617. doi: 10.1016/j.foodchem.2020.126617

Jiang, B., Zhang, Y., Guo, T., Zhao, H., and Jin, Y. (2019). Structural characterization of lignin and lignin-carbohydrate complex (LCC) from ginkgo shells (Ginkgo biloba L.) by comprehensive NMR spectroscopy. Polymers 10:736. doi: 10.3390/polym 10070736

Jiang, M. H., Zhu, L., and Jiang, J. G. (2010). Immunoregulatory actions of polysaccharides from Chinese herbal medicine. Expert Opin. Ther. Tar. 14, 1367-1402. doi: 10.1517/14728222.2010.531010

Lee, Y. G., Lee, H., Jung, J. W., Seo, K. H., Lee, D. Y., Kim, H. G., et al. (2019). Flavonoids from Chionanthus retusus (Oleaceae) flowers and their protective effects against glutamate-induced cell toxicity in HT22 cells. Int. J. Mol. Sci. 20:3517. doi: 10.3390/ijms20143517

Lieberman, A. P., Shakkottai, V. G., and Albin, R. L. (2019). Polyglutamine repeats in neurodegenerative diseases. Annu. Rev. Pathol. 14, 1-27 doi: 10.1146/ annurev-pathmechdis-012418-012857

Lin, W., Xing, S., Jin, Y., Lu, X., Huang, C., and Yong, Q. (2020). Insight into understanding the performance of deep eutectic solvent pretreatment on improving enzymatic digestibility of bamboo residues. Bioresour. Technol. 306, $123-163$.

Liu, Y., Fu, Y., Shao, Z., Zhang, F., and Qin, M. (2018). Effects of pH control with acetic acid/sodium acetate buffer on the hot-water extraction of poplar wood. J. Bioresour. Bioprod. 3, 9-13. doi: 10.21967/jbb.v3i1.108

Nagai, Y., Fujikake, N., Ohno, K., Higashiyama, H., Popiel, H. A., Rahadian, J., et al. (2003). Prevention of polyglutamine oligomerization and neurodegeneration by 
the peptide inhibitor QBP1 in Drosophila. Hum. Mol. Genet. 12, 1253-1259. doi: $10.1093 / \mathrm{hmg} / \mathrm{ddg} 144$

Pei, W., Shang, W., Liang, C. Jiang, X, Huang, C., and Yong, Q. (2020). Using lignin as the precursor to synthesize Fe3O4@lignin composite for preparing electromagnetic wave absorbing lignin-phenol-formaldehyde adhesive. Ind. Crop. Prod. 154:112638 doi: 10.1016/j.indcrop.2020.112638

Ralph, J. (2010). Hydroxycinnamates in lignification. Phytochem. Rev. 9, 65-83. doi: 10.1007/s11101-009-9141-9

Sakagami, H., Hashimoto, K., Suzuki, F., Ogiwara, T., Satoh, K., Ito, H., et al. (2005). Molecular requirements of lignin-carbohydrate complexes for expression of unique biological activities. Phytochemistry 66, 2108-2120. doi: 10.1016/j. phytochem.2005.05.013

Sakagami, H., Kushida, T., Oizumi, T., Nakashima, H., and Makino, T. (2010). Distribution of lignin-carbohydrate complex in plant kingdom and its functionality as alternative medicine. Pharmacol. Therapeut. 128, 91-105. doi: 10.1016/j.pharmthera.2010.05.004

Shen, X. J., Chen, T., Wang, H. M., Mei, Q., Yue, F., Sun, S., et al. (2020). Structural and morphological transformations of lignin macromolecules during bio-based deep eutectic solvent (DES) pretreatment. ACS Sustain. Chem. Eng. 8, 2130-3137 doi: 10.1021/acssuschemeng.9b05106

Singleton, V. L., and Rossi, J. A. (1965). Colorimetry of total phenolics with phosphomolybdic-phosphotungstic acid reagents. Am. J. Enol. Viticult. 16, 144-158.

Sluiter, A., Hames, B., Ruiz, R., Scarlata, C., Sluiter, J., Templeton, D., et al. (2011). Determination of Structural Carbohydrates and Lignin in Biomass. Laboratory Analytical Procedure (LAP), Technical Report NREL/TP-510-42618. National Renewable Energy Laboratory (NREL): Golden, CO.

Song, J. H., and Hong, S. P. (2020). Identity and localization of floral scent components in an androdioecious species, Chionanthus retusus (Oleaceae). J. Asia Pac. Biodiv. 13, 288-294. doi: 10.1016/j.japb.2020. 02.007

Sun, S. N., Li, M. F., Yuan, T. Q., Xu, F., and Sun, R. C. (2012). Sequential extractions and structural characterization of lignin with ethanol and alkali from bamboo (Neosinocalamus affinis). Ind. Crop. Prod. 37, 51-60. doi: 10. 1016/j.indcrop.2011.11.033

Ten, E., and Vermerris, W. (2013). Functionalized polymers from lignocellulosic biomass: state of the art. Polymers 5, 600-642. doi: 10.3390/polym502 0600

Ugartondo, V., Mitjans, M., and Vinardell, M. P. (2008). Comparative antioxidant and cytotoxic effects of lignins from different sources. Bioresour. Technol. 99, 6683-6687. doi: 10.1016/j.biortech.2007.11.038

Walter, G. M., Raveh, A., Mok, S. A., McQuade, T. J., Arevang, C. J., Schultz, P. J., et al. (2014). High-throughput screen of natural product extracts in a yeast model of polyglutamine proteotoxicity. Chem. Biol. Drug Des. 83, 440-449. doi: $10.1111 /$ cbdd.12259

Wang, H. M., Ma, C. Y., Li, H. Y., Chen, T. Y., Wen, J. L., Cao, X. F., et al. (2020). Structural variations of lignin macromolecules from early growth stages of poplar cell walls. ACS Sustain. Chem. Eng. 8, 1813-1822. doi: 10.1021/ acssuschemeng.9b05845

Wang, L., Oh, J.Y., Hwang, J., Ko, J.Y., Jeon, Y.J., and Ryu, B. (2019). In vitro and in vivo antioxidant activities of polysaccharides isolated from celluclast-assisted extract of an edible brown seaweed, sargassum fulvellum. Antioxidants 8:493. doi: 10.3390/antiox8100493

Wang, Z. K., Hong, S., Wen, J. L., Ma, C. Y., Tang, L., Jiang, H., et al. (2019). Lewis acid-facilitated deep eutectic solvent (DES) pretreatment for producing high-purity and antioxidative lignin. ACS Sustain. Chem. Eng. 8, 1050-1057. doi: 10.1021 /acssuschemeng.9b05846

Waris, G., and Ahsan, H. (2006). Reactive oxygen species: role in the development of cancer and various chronic conditions. J. Carcinogenes 5:14.

Wei, D. W., Wei, H., Gauthier, A. C., Song, J., Jin, Y., and Xiao, H. (2020). Superhydrophobic modification of cellulose and cotton textiles: method-ologies and applications. J. Bioresour. Bioprod. 5, 1-16. doi: 10.1016/j.jobab.2020.03. 001

Wu, Y., Tang, Q., Yang, F., Xu, L., Wang, X., and Zhang, J. (2019). Mechanical and thermal properties of rice straw cellulose nanofibrils-enhanced polyvinyl alcohol films using freezing-and-thawing cycle method. Cellulose 26, 31933204. doi: 10.1007/s10570-019-02310-6

Wu, Y. L., Chang, J. C., Lin, W. Y., Li, C. C., Hsieh, M., Chen, H. W., et al. (2017). Treatment with caffeic acid and resveratrol alleviates oxidative stress induced neurotoxicity in cell and drosophila models of spinocerebellar ataxia type3. Sci. Rep. 7, 1-12.

You, T. T., Zhang, L. M., Zhou, S. K., and Xu, F. (2015). Structural elucidation of lignin-carbohydrate complex (LCC) preparations and lignin from Arundo donax Linn. Ind. Crop. Prod. 71, 65-74. doi: 10.1016/j.indcrop.2015.03.070

Yuan, T. Q., Sun, S. N., Xu, F., and Sun, R. C. (2011). Characterization of lignin structures and lignin-carbohydrate complex (LCC) linkages by quantitative 13C and 2D HSQC NMR spectroscopy. J. Agric. Food Chem. 59, 10604-10614. doi: $10.1021 /$ jf 2031549

Zacharias, D. A., Violin, J. D., Newton, A. C., and Tsien, R. Y. (2002). Partitioning of lipid-modified monomeric GFPs into membrane microdomains of live cells. Science 296, 913-916. doi: 10.1126/science.1068539

Zhang, L., and Gellerstedt, G. (2007). Quantitative 2D HSQC NMR determination of polymer structures by selecting suitable internal standard references. Magn. Reson. Chem. 45, 37-45. doi: 10.1002/mrc.1914

Zhang, Y., Wang, S., Xu, W., Cheng, F., Pranovich, A., Smeds, A., et al. (2018). Valorization of lignin-carbohydrate complexes from hydrolysates of norway spruce: efficient separation, structural characterization, and antioxidant activity. ACS Sustainable Chem. Eng. 10, 1447-1456. doi: 10.1021/acssuschemeng. $8 \mathrm{~b} 05142$

Zhao, Z., Hayashi, S., Xu, W., Wu, Z., Tanaka, S., Sun, S., et al. (2018). A novel eco-friendly wood adhesive composed by sucrose and ammonium dihydrogen phosphate. Polymers 10:1251. doi: 10.3390/polym10111251

Zhao, Z. Y., Zhang, Q., Li, Y. F., Dong, L. L., and Liu, S. L. (2015). Optimization of ultrasound extraction of Alisma orientalis polysaccharides by response surface methodology and their antioxidant activities. Carbohydr. Polym. 119, 101-109. doi: 10.1016/j.carbpol.2014.11.052

Zhou, X., and Xu, Y. (2019). Eco-friendly consolidated process for co-production of xylooligosaccharides and fermentable sugars using self-providing xylonic acid as key pretreatment catalyst. Biotechnol. Biofuels 12:272.

Conflict of Interest: The authors declare that the research was conducted in the absence of any commercial or financial relationships that could be construed as a potential conflict of interest.

Copyright $\odot 2020$ Pei, Chen, Chan, Zheng, Liang and Huang. This is an open-access article distributed under the terms of the Creative Commons Attribution License (CC BY). The use, distribution or reproduction in other forums is permitted, provided the original author(s) and the copyright owner(s) are credited and that the original publication in this journal is cited, in accordance with accepted academic practice. No use, distribution or reproduction is permitted which does not comply with these terms. 